
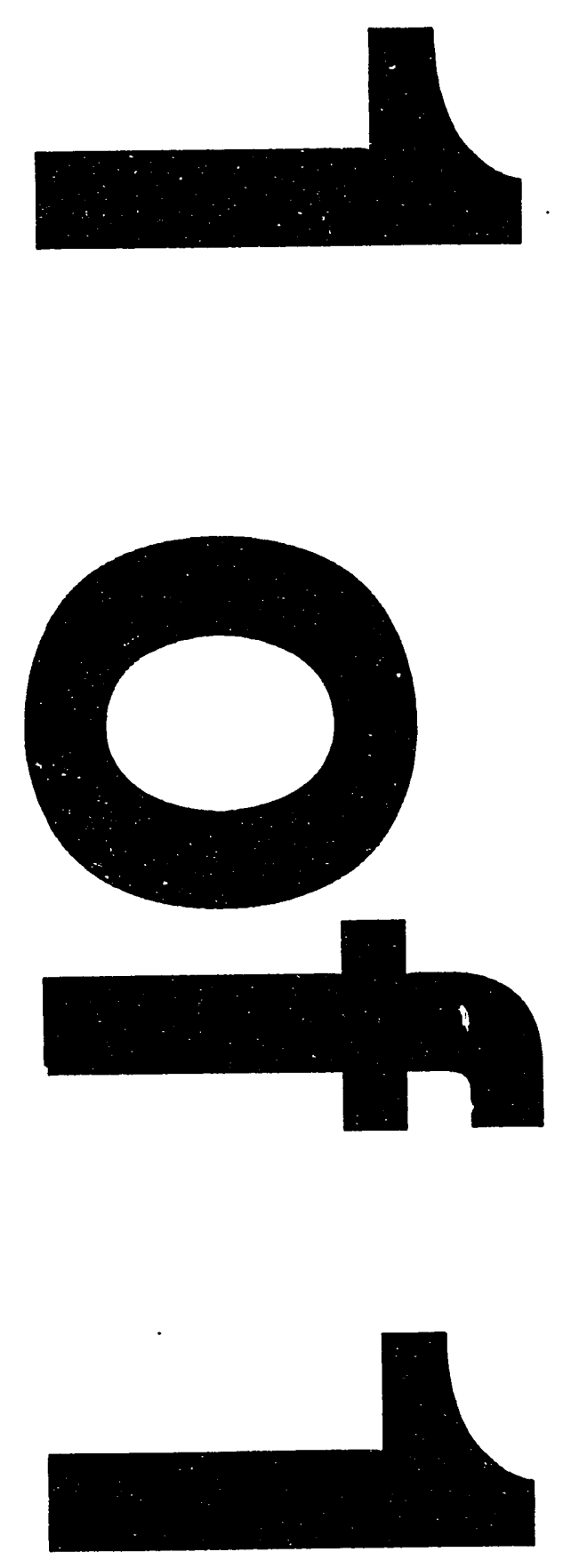


\title{
KEY DESIGN REQUIREMENTS FOR LONG-REACH MANIPUL.ATORS
}

\author{
D. S. Kwon \\ S. March-Leuba \\ S. M. Babcock \\ W. R. Hamel
}

Robotics \& Process Systems Division

Oak Ridge National Laboratory

NOTICE This document contains information of a pre minary nature.

It is subject to revision or correction and therefore does not represent a final report.

\section{SEPTEMBER 1993}

Prepared by the

OAK RIDGE NATIONAL LABORATORY

Oak Ridge, Tennessee 37831-6285

managed by

MARTIN MARIETTA ENERGY SYSTEMS, INC.

for the

U.S. DEPARTMENT OF ENERGY

under contract DE-AC05-84-OR21400 


\section{CONTENTS}

\section{Page}

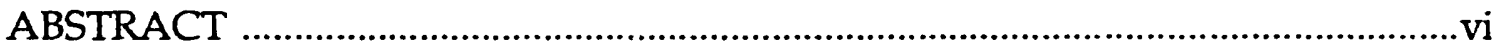

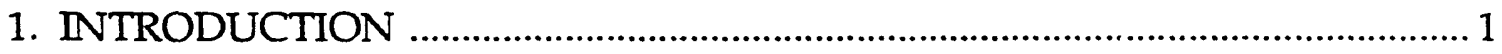

1.1 APPLICATIONS IN THE ENVIRONMENTAL RESTORATION

AND WASTE MANAGEMENT PROGRAM ………............................ 1

1.2 FOCUS OF REPORT WWASTE STORAGE TANK

REMEDIATION …………………….......................................... 1

1.2.1 Remediation Approach .............................................................. 1

1.2.2 Retrieval Manipulator ............................................................ 2

1.3 IMPLICATIONS OF LONG-REACH MANIPULATION ..................... 2

1.4 SUMMARY OF CONTENTS ......................................................................... 3

2. REQUIREMENTS FOR WASTE STORAGE TANK REMEDIATION ................. 4

2.1 FUNCTIONAL REQUIREMENTS .......................................................4

2.1.1 Telerobotic Operation ..................................................................... 4

2.1.2 Avoidance of Loading the Tank Structure …………….............4

2.1.3 Failure Recovery …………………………………………...... 4

2.2 KINEMATIC REQUIREMENTS ………………................................

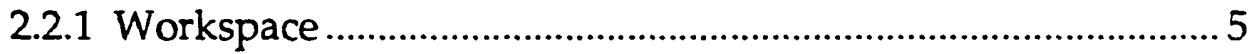

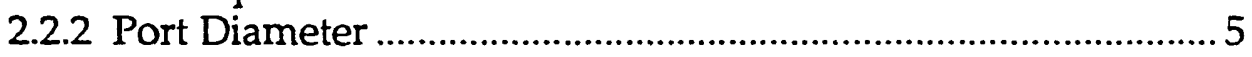

2.2.3 Deployment ........................................................................... 5

2.2.4 Number of Degrees of Freedom ……………………................. 5

2.2.5 Tower Height …………………………………………….....

2.2.6 Transportability ........................................................................

2.3 PERFORMANCE REQUIREMENTS ...................................................

2.3.1 Payload ................................................................................. 6

2.3.2 Position Accuracy and Repeatability .......................................... 6

2.3.3 No-load and Maximum Load Velocity ...................................... 6

2.3.4 Static and Dynamic Performance................................................ 6

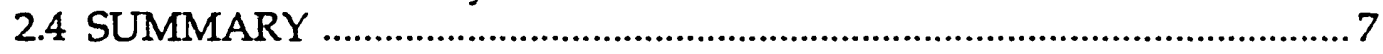

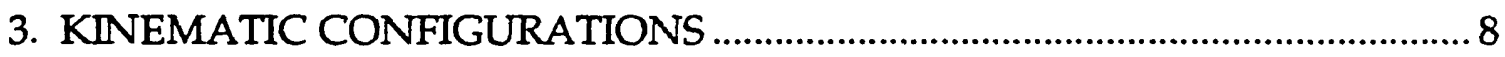

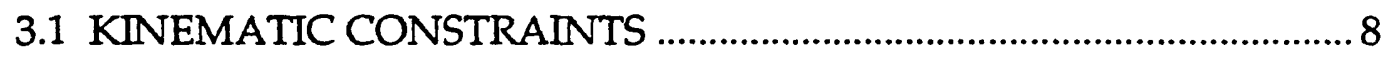

3.2 COMPARISON OF POTENTIAL CONFIGURATIONS ........................ 9

3.2.1 Reference Configurations........................................................

3.2.2 Manipulator Deployment Inside the Tank .............................10

3.3 ANALYSIS OF REFERENCE KINEMATIC

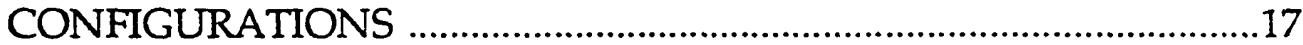

3.3.1 Necessity of Each Degree of Freedom.......................................17

3.3.1.1 First Degree of Freedom: Rotational Joint .................17

3.3.1.2 Second Degree of Freedom: Prismatic Joint ...............17 
3.3.1.3 Third and Fifth Degree of Freedom:

Rotational Joints .18

3.3.1.4 Fourth Degree of Freedom: Extra Rotational Joints

3.3.1.5 Sixth Degree of Freedom: Prismatic versus Rotational Joints

3.3.1.6 Tower Height Summary ........................................21

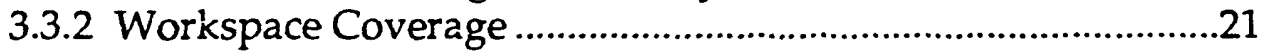

3.3.3 Failure Recovery ..............................................................22

3.4 SUMMARY OF ADVANTAGES OF THE ADDITIONAL

ROLL

4. PARAMETRIC STUDY OF LONG-REACH MANIPULATOR DESIGNS .26

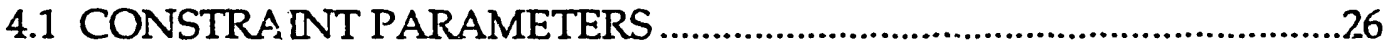

4.2 ASSUMPTIONS FOR THE MANIPULATOR DESIGN …..................26

4.2.1 Waste Level ........................................................................27

4.2.2 Entrance Port Location and Diameter ....................................27

4.2.3 Actuator Power Capacity and Weight ....................................27

4.2.4 Deflection .............................................................................27

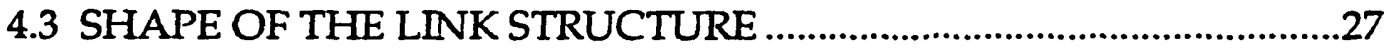

4.4 OPTIMAL DESIGN OF THE MANIPULATOR LINKS $\ldots \ldots \ldots \ldots \ldots \ldots \ldots . . . \ldots \ldots$

4.4.1 Allowable Link Characteristic Diameter ..............................27

4.4.2 Structural Strength Criteria ................................................28

4.4.3 Static Deflection Criteria ......................................................28

4.4.4 Optimization of the Structure Size ........................................28

4.5 PARAMETRIC DESIGN ANALYSIS PROCEDURES ........................29

4.6 ANALYSIS OF PARAMETRIC DESIGN RESULTS............................29

4.6.1 Case 1: Varying the Static Deflection Requirement with Different Payloads for the TSET Manipulator. ...............31

4.6.2 Case 2: Varying the Entrance Hole Diameter with Different Tank Sizes for TSET Manipulator.

4.6.3 Case 3: Varying the Static Deflection Requirement with Different Payloads for the Folded Type

Manipulator.

4.6.4 Case 4: Varying the Entrance Hole Diameter with Different Tank Sizes for the Folded Type Manipulator .42

4.7 CONCLUSIONS OF THE PARAMETRIC DESIGN ANALYSIS ........45

4.7.1 Static Deflection ..................................................................45

4.7.2 Column Static Deflection ....................................................46

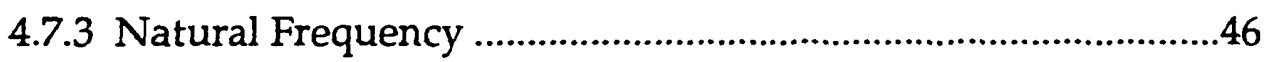




\section{Page}

4.7.4 Entrance Hole Diameter .........................................................46

4.7.5 Manipulator Type ............................................................... 46

\section{ADVANTAGES AND DISADVANTAGES OF MANIPULATOR}

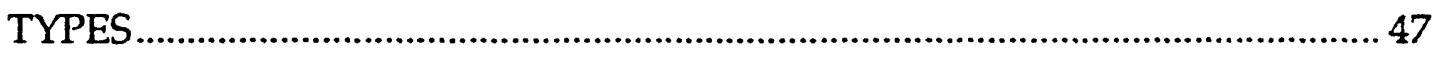

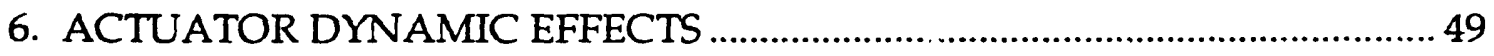

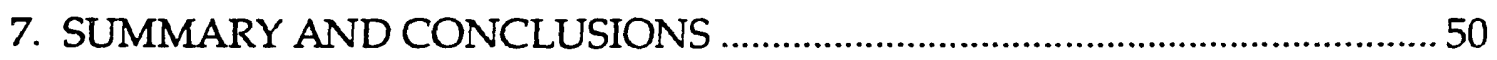

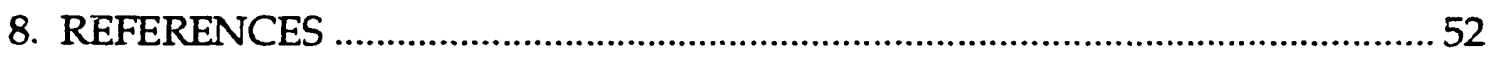




\section{LIST OF FIGURES}

Figure

1. Nominal waste storage tank dimensions in $\mathrm{ft}$............................................ 8

2. Long-reach manipulator deployed inside a waste storage tank. ................ 9

3a. Suggested REPRPF configuration .................................................................11

3b. Suggested REPRPP configuration ...............................................................11

4. Folded-entry-type long-reach manipulator deployment. ...........................13

5. Telescopic-sequential-entry-type long-reach manipulator deployment....14

6a. Sequential-entry-type long-reach manipulator deployment (tank diameter/clearance <3).

6b. Sequential-entry-type long-reach manipulator deployment (tank diameter/clearance $>3$ ).

7. Symmetric workspace of a robot with a first rotational joint. .....................18

8. Waste storage tank space to be covered.........................................................18

9. Waste storage tank and telescopic column dimensions. ….........................19

10a. Long-reach manipulator in a SCARA configuration avoiding an obstacle

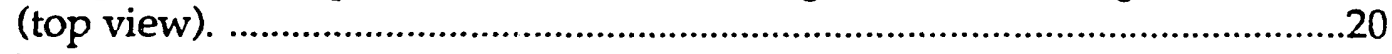

10b. Long-reach manipulator in a SCARA configuration avoiding an obstacle

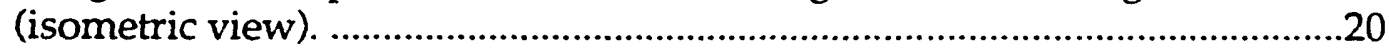

11. Workspace of the FET case when $\mathrm{L} 2=11 \mathrm{ft}, \mathrm{L} 3$ varies from 11 to $27 \mathrm{ft}$, shoulder angle goes from $-50^{\circ}$ to $90^{\circ}$, and elbow angle from $-180^{\circ}$ to $-40^{\circ}$ $\left(-180^{\circ}\right.$ to $100^{\circ}$ taking into account the extra roll effect $)$.

12. Workspace of the TSET case when $\mathrm{L} 2=11 \mathrm{ft}$, $\mathrm{L} 3$ varies from 11 to $27 \mathrm{ft}$, shoulder angle goes from $-90^{\circ}$ to $50^{\circ}$, and elbow angle from $-140^{\circ}$ to $0^{\circ}$ $\left(-140^{\circ}\right.$ to $140^{\circ}$ with the extra roll).

13. Workspace of the SET case when $\mathrm{L} 2=16 \mathrm{ft}, \mathrm{L} 3=\mathrm{L} 4=11 \mathrm{ft}$, shoulder angle goes from $-90^{\circ}$ to $50^{\circ}$, elbow angle from $-140^{\circ}$ to $0^{\circ}\left(-140^{\circ}\right.$ to $140^{\circ}$ with the extra roll), and the last pitch angle from $-70^{\circ}$ to $70^{\circ}$. ....................................24

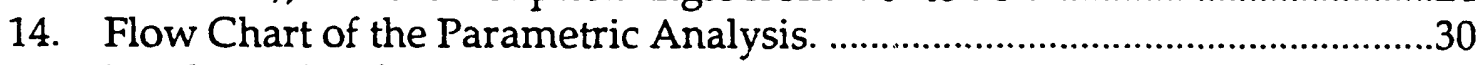

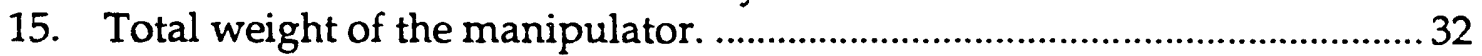

16. Natural frequency with maximum payload. …………………………........32

17. Natural frequency with no payload. .........................................................33

18. Column size versus static deflection design criteria. .......................................34

19. No-load static deflection versus static deflection design criteria.................34

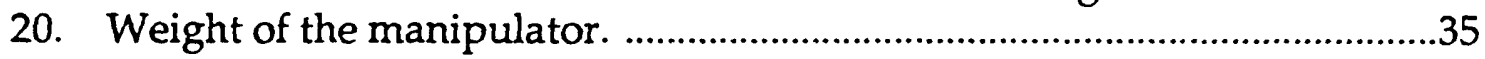

21. Natural frequency with maximum payload. .................................................36

22. Natural frequency with no payload. ............................................................

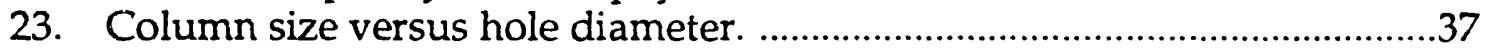

24. Static deflection with maximum payload. .....................................................37

25. Static deflection with maximum payload. .......................................................38

26. Total weight of the manipulator.................................................................... 39

27. Natural frequency with maximum payload. .................................................40 


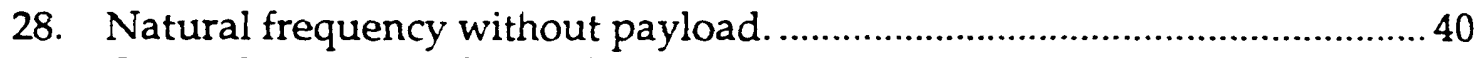

29. Outer dimension of the column. ...........................................................4 41

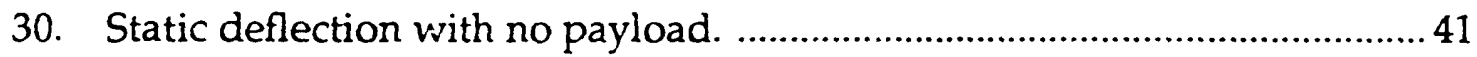

31. Manipulator weight versus hole diameter. ..................................................42

32. Natural frequency with maximum payload. ..................................................43 43

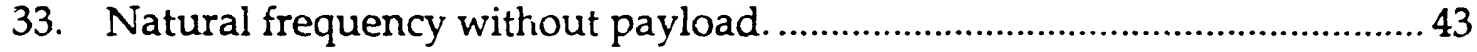

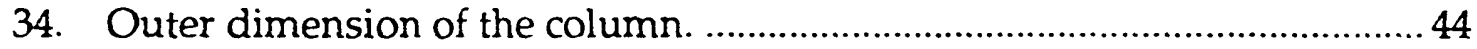

35. Static deflection with maximum payload....................................................4 44

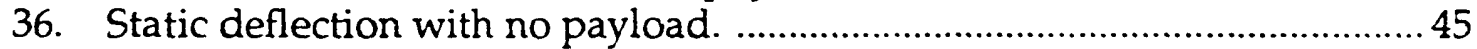




\begin{abstract}
Long-reach manipulators differ from industrial robots and teleoperators typically used in the nuclear industry in that the aspect ratio (length to diameter) of links is much greater and link flexibility, as well as joint or drive train flexibility, is likely to be significant. Long-reach manipulators will be required for a variety of applications in the Environmental Restoration and Waste Management Program. While each application will present specific functional, kinematic, and performance requirements, an approach for determining the kinematic applicability and performance characteristics is presented, with a focus on waste storage tank remediation. Requirements are identified, kinematic configurations are considered, and a parametric study of link design parameters and their effects on performance characteristics is presented.
\end{abstract}




\section{INTRODUCTION}

\subsection{APPLICATIONS IN THE ENVIRONMENTAL RESTORATION AND WASTE MANAGEMENT PROGRAM}

As noted in the Environmental Restoration and Waste Management Robotics Technology Development Program Robotics 5-Year Program Plan, "A characteristic of most of the waste remediation application areas is that manipulation systems will be required to have a significantly larger work space volume and higher payload capacity than currently available" [DOE 1991]. Included in the potential application areas are waste storage tank remediation, buried waste retrieval, and decontamination and decommissioning.

\subsection{FOCUS OF REPORT-WASTE STORAGF TANK REMEDIATION}

Of the potential application areas, waste storage tank remediation is of major interest. A number of the U.S. Department of Energy (DOE) sites have large waste storage tanks that require remediation. The initial waste storage tanks were commonly designed as single-shell tanks, which makes monitoring for leakage very difficult or nearly impossible. In several cases, Tri-Party Agreements between DOE, state agencies, and the U.S. Environmental Protection Agency (EPA) have been made which contain extensive remediation commitments. Current EPA regulations require double-shell tanks for waste storage; hence, many DOE sites are out of compliance with current EPA regulations.

\subsubsection{Remediation Approach}

A number of studies of different approaches to remediation of the waste storage tanks have been performed at the various sites. The most basic conclusion of these studies is that approaches that involve the addition of large quantities of water for dislodging and sluicing waste are not desirable because of the required processing of the water as waste and the additional risk of loss of contaminated liquids through leaks in the tanks. Sluicing is the most common approach, and efforts to minimize the addition of water have been investigated. However, in many cases, because of the crystalline content and insolubility of the waste, sluicing is not applicable. This has led to two approaches: one that involves the use of a large, long-reach manipulation system with a variety of end-effectors for dislodging the waste and a second that involves the use of a mobile platform with more classical manipulation capabilities and appropriate end-effectors to be deployed within tanks.

For the long-reach manipulation approach, remediation would be accomplished with several subsystems, including the retrieval manipulation system and associated end-effectors, in-tank material transfer systems, 
above ground waste handling and transfer systems, and a variety of support systems. The various subsystems of the remediation system would be supported by a structure that spans the tank to avoid loading the dome of the tank. Containment would be provided and equipment would be remotely controlled. A combination of teleoperation and robotic operation of the equipment would be employed. A single remediation system would be used in the remediation of a number of tanks and would be disassembled to the extent necessary for transport between tanks.

\subsubsection{Retrieval Manipulator}

The retrieval manipulator would provide positioning and orientation of a variety of end-effectors. In addition, it may be required to position a material transfer system that would be attached to one or more end-effectors designed for dislodging and mobilizing waste. Deployment of the retrieval manipulator into a tank that is full of waste may be necessary to initiate remediation. The retrieval manipulator may consist of a high-capacity, long-reach manipulator (LRM) and one or more "dexterous, short-reach" manipulators that may be remotely disconnected from the LRM. LRM capacities in the range of 500 to $1500 \mathrm{lb}$ would be required. The LRM would be designed to provide positioning and orientation throughout the tank volume. It would incorporate a variety of service lines for the operation of end-effectors. Ease of decontamination is a significant design issue. Scheduled maintenance during the remediation of a single tank is not desirable. Modularity would be desired to allow ease of replacement of failed components.

\subsection{IMPLICATIONS OF LONG-REACH MANIPULATION}

As noted in the Robotics 5-Year Plan, "While adaptation of existing robotics technology will allow early attention to selected remediation tasks, significant advanced technology development will be required to address some engineering problems (e.g., reducing the structural vibrations and deflections of such manipulators) associated with long manipulators with large payload requirements" [DOE 1991]. The time required to remediate a waste tank will be significantly impacted by the fundamental natural frequency of the LRM, the amplitude of tip vibration, and the ability of the control system to damp vibration initiated by motion of either the LRM or a dexterous manipulator at the end or by end-effector forces. The ability to perform some tasks will be impacted by positioning accuracy and force control. A driving factor in the design of a long-reach manipulation system for waste tank remediation is the diameter of the entrance port. This dimension, when combined with the tank dimensions and required capacity, determines the magnitude of the design and control problem. 


\subsection{SUMMARY OF CONTENTS}

The report addresses key design issues for LRMs which will have an important role in determining the performance of a retrieval manipulator for waste tank remediation. The design of the manipulator structure is discussed primarily from the perspective of the implications of such parameters as capacity, vertical and horizontal reach (storage tank height and radius), access port diameter and vertical tower (above-ground) height on kinematic configuration, weight, fundamental natural frequency, and static deflection. Section 2 contains functional, kinematic, and performance requirements and a summary of what might be considered key design requirements.

In Sect. 3, two basic kinematic configurations are presented, together with variations of each primarily due to alternate approaches for deployment of the manipulator through a constrained port in a tank. An analysis is performed to demonstrate the necessity or advantage of each degree of freedom (DOF) of the basic configurations considered.

Section 4 presents a parametric study of LRM designs for payloa !, horizontal reach, access hole diameter, and static deflection criteria variations. Constraints and assumptions are discussed, types of manipulator structures considered are identified, and criteria for link design are listed. The procedure developed for parametric design is then described, fo"iowed by an analysis of the results of the study. Conclusions from the parametric analysis are summarized.

In Sect. 5, the advantages and disadvantages of various kinematic configurations are summarized. Section 6 contains a brief discussion of the effects of actuator dynamics. Finally, a summary with conclusions is presented in Sect. 7. 


\section{REQUIREMENTS FOR WASTE STORAGE TANK REMEDIATION}

The basic requirements for an LRM for use in waste storage tank remediation can be grouped as functional requirements, kinematic requirements, and performance requirements.

\subsection{FUNCTIONAL REQUIREMENTS}

\subsubsection{Telerobotic Operation}

The manipulator must be designed for telerobotic operation, that is, it must be suited for operation as both a teleoperator and a robotic manipulator. In the teleoperation mode, it is not anticipated that force reflection will be required. However, the inclusion of this capability may allow the application of the LRM, without an auxiliary dexterous manipulator mounted on the end, to perform tasks requiring force control with heavy end-effectors but not high positioning precision. In the robotic mode, the manipulator will be required to follow preplanned trajectories or trajectories that have been taught in the teleoperation mode. The trajectory plarning approach should avoid exciting the manipulator's structural vibration modes. It should include obstacle avoidance capability and approaches to resolve the kinematic redundancy. Potential robotic mode operations include manipulator deployment, automatic tool changing, and repetitive characterization and retrieval tasks.

\subsubsection{Avoidance of Loading the Tank Structure}

Typically, systems designed for the remediation of waste storage tanks must not apply significant loads to the tanks. Support must be provided by a structure that spans the tank, and adequate clearance must be provided between equipment inserted for remediation and the tank port.

\subsubsection{Failure Recovery}

Provisions must be made to ensure that under any single failure situation, equipment can be removed from a waste storage tank. This requirement is cost driven by the high cost of providing additional equipment and an additional port through which it could be deployed to repair or aid in the retrieval of the manipulator. 


\subsection{KINEMATIC REQUIREMENTS}

\subsubsection{Workspace}

Single-shell waste storage tanks are typically vertical cylinders with a flat bottom and domed roof. LRMs for remediation must have a workspace that is nearly as large as the tank volume, assuming that some tasks will be performed without the addition of a dexterc $x$ manipulator on the end.

\subsubsection{Port Diameter}

LRMs will most likely be designed for deployment through existing ports, which vary from $\sim 24$ to 42 in. in diameter.

\subsubsection{Deployment}

An LRM may be required to be deployed within the dome clearance above the maximum waste height. It is unlikely that the waste would be higher than the cylindrical portion of the tank. (Only Silo 3 at Fernald is known to be filled above the wall.)

\subsubsection{Number of Degrees of Freedom}

To provide general purpose positioning, LRMs must have at least $3 \mathrm{DOF}$. Workspace and deployment requirements may dictate additional DOF, given specific tank requirements. Additional DOF may be required for end-effector orientation.

\subsubsection{Tower Height}

The tank configuration, workspace requirements, deployment approach, and number of DOF of the manipulator will impact the height of the tower required for support of the manipulator. Unnecessarily high support towers may significantly affect costs and make installation and removal difficult.

\subsubsection{Transportability}

Typically, a single system will be used for the remediation of multiple tanks. Provisions are needed for the initial installation of the LRM and for removal and transport to other tank sites or a maintenance facility. The ease with which this requirement can be satisfied will be impacted by the degree to which the manipulator can be collapsed to a minimum length and the maximum height required to lift the manipulator above a tank. 


\subsection{PERFORMANCE REQUIREMENTS}

\subsubsection{Payload}

LRM payload requirements are likely to vary between 500 and $1500 \mathrm{lb}$. Dynamic loading will be dependent on specific end-effectors.

\subsubsection{Position Accuracy and Repeatability}

Position accuracy and repeatability requirements will be dependent on tasks to be performed. For the initial remediation of tanks, which involves removal of 90 to $95 \%$ of the waste, position accuracy requirements are likely to be relatively low (of the order of several inches). Repeatability requirements will be more stringent (of the order of 1 in.), driven primarily by a requirement for automatic changing of end-effectors. Note that because of the static and dynamic deflections of the manipulator links, end-point position measurement may be required to provide reasonable accuracy and repeatability. For removal of the last 5 to $10 \%$ of the waste, these requirements may be more stringent to work in closer proximity to the tank surfaces or possibly in contact with tank surfaces. However, it is likely that surface contact will be performed using a dexterous manipulator attached to the end of the LRM.

\subsubsection{No-load and Maximum Load Velocity}

No-load and maximum load tip velocity requirements are likely to be low (of the order of $50 \mathrm{in.} / \mathrm{s}$ ) in comparison to smaller industrial robots, which, if scaled up, would produce much larger tip velocities for the same joint angular velocities (of the order of $500 \mathrm{in} / \mathrm{s}$ ). For operations requiring large motions, such as changing end-effectors and transfer of in-tank hardware to a removal system, higher velocity motions would reduce the task time. However, it is expected that these types of motions will comprise a small portion of the total remediation time. The basic velocity constraint will be an upper bound that will ensure that collisions can be avoided given the dynamic response of the manipulator, including its flexibility.

\subsubsection{Static and Dynamic Performance}

The static deflection of an LRM will be nonlinearly inversely related to the manipulator's weight. While there is no obvious limitation associated with weight, there is no obvious limitation associated with static deflection other than the associated vibration amplitude that is likely to occur. Static deflections on the order of 4 to 8 in. would be acceptable, given that a true end-point position measurement can be made.

The fundamental natural frequency of the LRM will be related to the static deflection and will band limit the control of the manipulator if a joint servo 
approach is used. The manipulator will not be operated as a dexterous teleoperator; therefore, it is not necessary for the manipulator to have a bandwidth comparable to that of a human operator. Fundamental natural frequencies of the order of 1 to $3 \mathrm{~Hz}$ will be acceptable. The LRM will likely be operated in a resolved rate mode as a teleoperator as well as in a pure robotic mode. In addition, combinations of these two modes are likely in order to provide constrained teleoperation or obstacle avoidance.

More important than static deflection and fundamental natural frequency are the damping characteristics of the manipulator. Research in the control of flexible manipulators includes active damping algorithms using a flexible manipulator's actuators and the motion of a dexterous manipulator mounted on the end of the flexible manipulator and passive damping of the structure. The effective damping of inevitable vibrations induced by motion of the LRM or end-effector loading is the key to the overall remediation time and the performance of some tasks.

\subsection{SUMMARY}

The key design requirements are those associated with functional requirements of not loading the tank structure and the ability to recover from failures, the kinematic constraints of deployment in a constrained space and covering the entire workspace, and the dynamic performance constraint related to vibration damping. 


\section{KINEMATIC CONFIGURATIONS}

\subsection{KINEMATIC CONSTRAINTS}

A large cost advantage results if the retrieval of waste from storage tanks can be done using existing manholes. To avoid loading the tank structure, the retrieval system will not be allowed to touch the walls, dome, or manhole of the tanks under any condition. The nominal storage tank used in this study is that shown in Fig. 1, which is $75 \mathrm{ft}$ in diameter and $30 \mathrm{ft}$ high, not conside:ing the domed roof. It has a dome height of $12 \mathrm{ft}$ and is buried $8 \mathrm{ft}$ below the ground surface. A 2 -ft clearance is provided above the surface, accounting finally for a workspace $52 \mathrm{ft}$ deep and $75 \mathrm{ft}$ in diameter. The walls and dome of the tank are made of concrete. There is a cylindrical steel liner inside the tank along the walls and bottom. The waste is assumed to be contained in the liner and therefore is at most $30 \mathrm{ft}$ deep. Given these nominal dimensions and a central access port, the LRM has to have a vertical reach of $52 \mathrm{ft}$ and a horizontal reach of $37.5 \mathrm{ft}$.

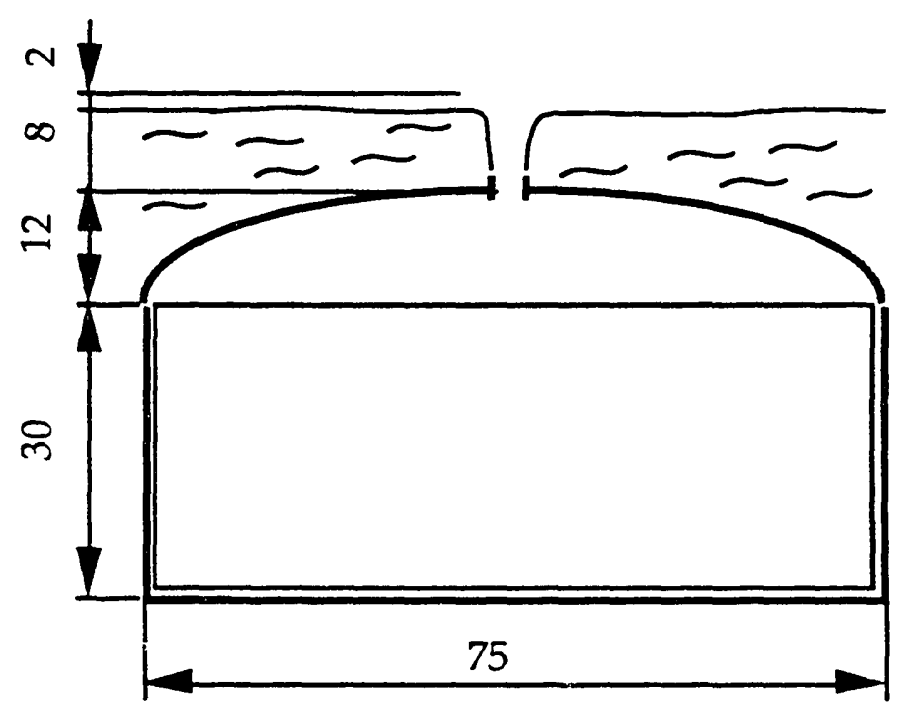

Fig. 1. Nominal waste storage tank dimensions in $\mathrm{ft}$.

The retrieval system has to be able to be deployed into the dome clearance height and then cover all the workspace defined by the liner and dome without inadvertently loading the walls or the dome. To avoid unnecessary contamination of the manipulator, only the end-effectors should come in contact with the waste. This means that at the beginning of the remediation, there may be only $12 \mathrm{ft}$ of clearance between the waste and the dome in which the LRM has to work.

A CimStation [Silma 1991] model of a manipulator already deployed inside the tank is shown in Fig. 2. 


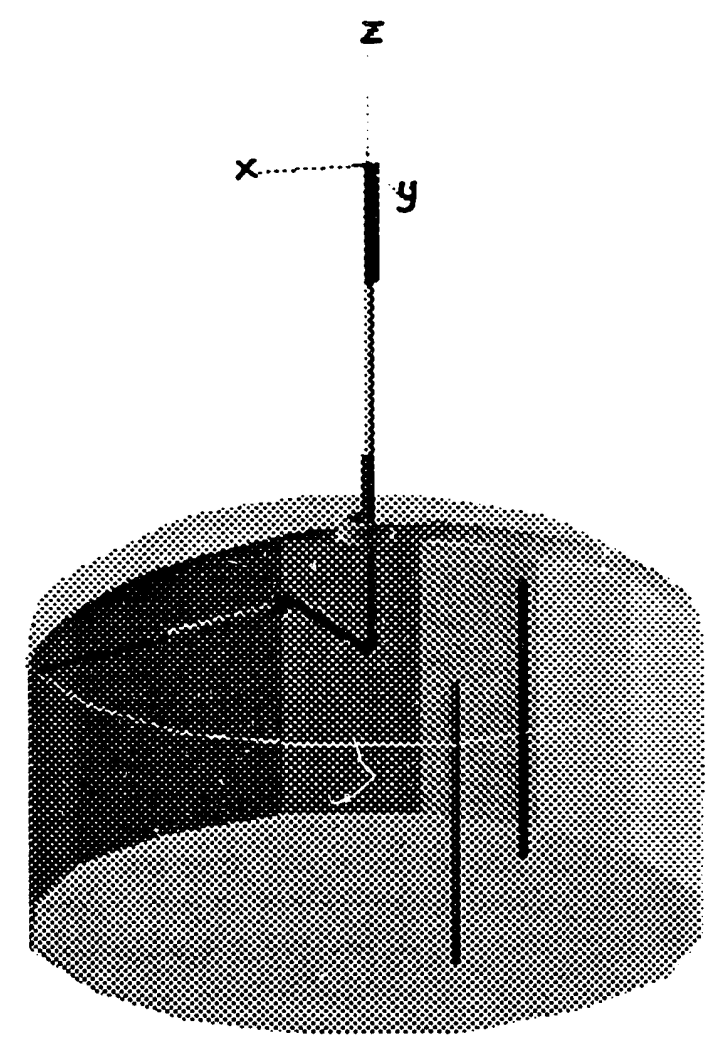

Fig. 2. Long-reach manipulator deployed inside a waste storage tank.

\subsection{COMPARISON OF POTENTIAL CONFIGURATIONS}

\subsubsection{Reference Configurations}

Two similar configurations, shown in Figs. $3 \mathrm{a}$ and $3 \mathrm{~b}$, have been identified as potential candidates for an LRM for waste storage tank remediation. Each is a 6-DOF positioning device. The first configuration is a roll-extend-pitch-rollpitch-extend (REPRPE) manipulator. The second has a final "pitch" rather than an "extend" DOF, making it a roll-extend-pitch-roll-pitch-pitch (REPRPP) manipulator. These configurations attempt to provide a maximum workspace while allowing deployment through the tank ports into the constrained volume of the waste storage tank dome. Note that a manipulator with three pitch joints can only be deployed into a tank with a vertical clearance that is greater than or equal to one-third of the desired horizontal reach.

Both structures should be considered to be positioning devices and do not include orientation that would be provided by a wrist or dexterous manipulator mounted at the end of the LRM. A number of different tools with different characteristics will be used in the waste retrieval procedures. 
Of the configurations considered previously [Jansen 1992], an REPPE kinematic configuration appeared to cover the workspace best; however, an REPPP configuration was not considered. The addition of the extra rotational DOF in this study between the two pitches provides a degree of redundancy, which allows the possibility of tilting the piane of the lower DOF. The rotational base will assure that the manipulator covers the solid of revolution that constitutes the space of the waste storage tanks.

The column, or first prismatic joint, will translate the solid of revolution vertically, covering all the space while minimizing the overall length of the manipulator. This column will also allow the LRM to be collapsed, reducing the height of the tower that will support it, and will make transportation of the manipulator from one tank to another easier to accomplish.

The shoulder and elbow pitches of the LRM are part of the classical configuration of a rotational manipulator. These two rotational joints give a maximum workspace and speed for minimum link lengths.

The extra rotational DOF between the two pitches allows the LRM to work in a SCARA, an elbow up or down, or an intermediate configuration. These different configurations give the LRM obstacle avoidance capability. Also, different configurations are better for different tasks and paths to be followed. For heavy payloads or controlled vertical motion, an elbow up or down configuration may be best; but for obstacle avoidance or a controlled horizontal motion, a SCARA configuration may be best. It may be possible to optimize the configuration of the manipulator to most effectively actively damp vibration.

Finally, the last extension or pitch allows the manipulator to reach both the closest and the more distant points inside the storage tank without interfering with the waste or the dome of the waste storage tank. In the extension case, it minimizes the required manipulator length for a given task, thus minimizing potential vibrational effects and static deflection.

\subsubsection{Manipulator Deployment Inside the Tank}

One of the most severe constraints that LRMs must satisfy is associated with deployment through ports that are very small compared with the workspace to be covered. Furthermore, this must be possible in the dome above the highest possible waste level.

Three feasible solutions are presented in this report for the deployment of the LRM. One solution is to introduce the manipulator folded up and to unfold it inside the tank above the surface of the waste. Figure 4 displays the deployment of a folded-entry-type (FET) LRM. Note that an extendible, or prismatic, joint is added at the last link to provide full coverage of the workspace. The deployment of this type of manipulator would not be restricted by the presence of risers or other objects and would not require the removal of waste to provide clearance. 


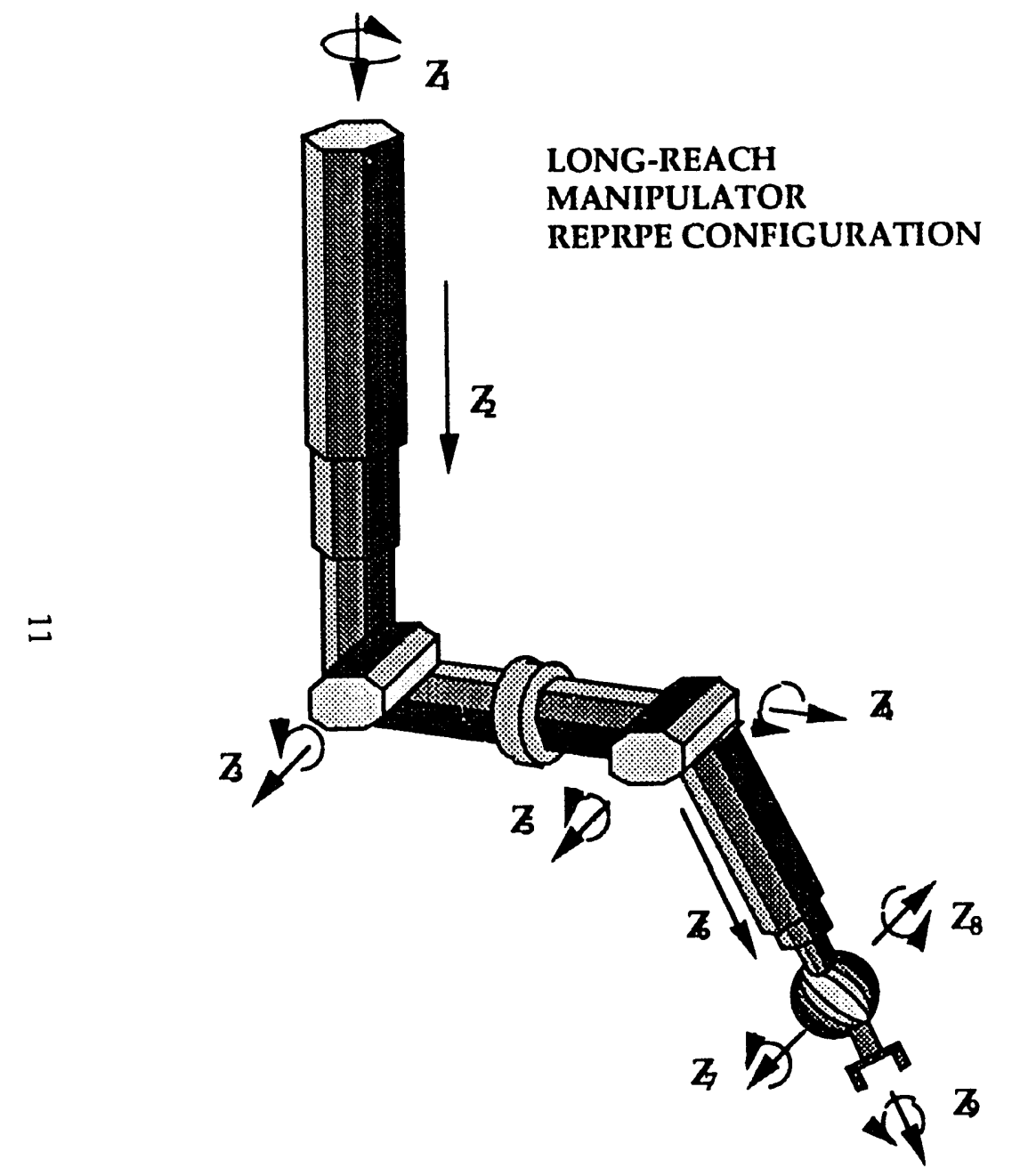

Fig. Ba. Suggested REPRPE configuration.

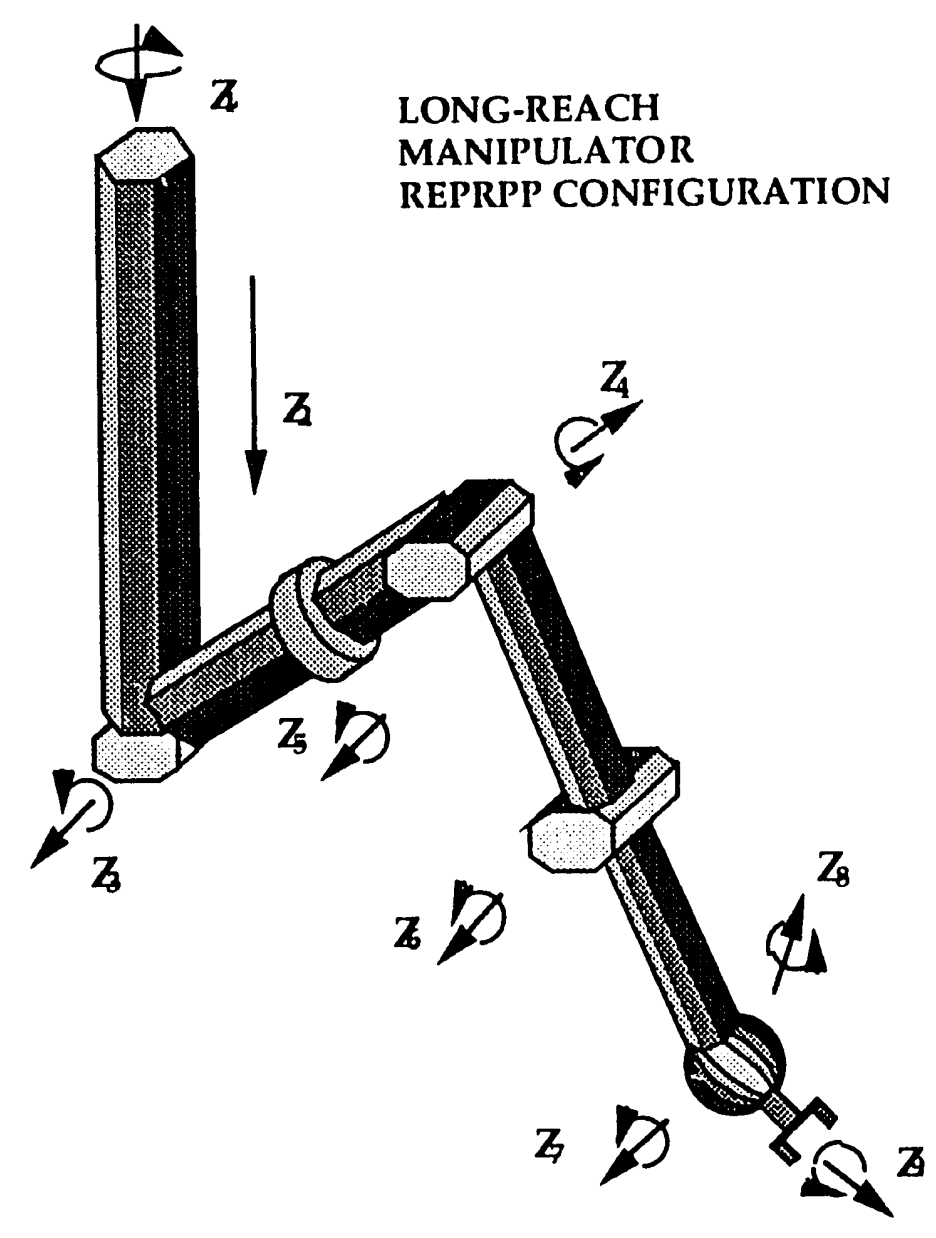

Fig. Bb. Suggested REPRPP configuration. 
Another feasible solution would be to introduce the links of the manipulator sequentially. One link after the other is introcuced and moved to aliow the next to go in. Preliminary planning is necessary to deploy this type because the links already introduced may have to be moved to avoid obstacles. Two manipulator configurations are considered in this case. Figure 5 shows the telescopicsequential-entry-type (TSET) LRM, which has the same kinematic configuration as the FET but is not foldable. The TSET manipulator needs a higher external support tower than the FET because all the links have to be straight to be introduced.

A different kinematic configuration composed only of rotational joints, with the exception of the prismatic column, is shown in Fig. 6a. The sequential-entrytype (SET) LRM has a revolute joint at the end link rather than a prismatic joint. This configuration requires the highest suppo:t tower and planning to avoid obstacles during deployment but has the advantages of rotational joints that include higher speeds and less backlash.

A different strategy is to introduce only the last link, or the two last links, of the arm to clear a hole that will allow the rest of the manipulator to be inserted inside. The configurations shown in Figs. 4, 5, and 6a will allow the LRM to be deployed and work in all of the workspace between the waste and the dome without the need of removing some of the waste. Figure $6 \mathrm{~b}$ shows that the SET configuration may require some initial waste removal to allow deployment of the manipulator, depending on the ratio of the tank diameter to the clearance above the waste. The deployment of the SET shown in Fig. 6a is only valid as long as the free space between the top of the waste and the top of the dome is greater than one-sixth of the diameter of the tank. For larger ratios of the tank diameter to clearance between waste and dome, only the last two links would be freely introduced inside the tank. Using these links, a hole in the waste would have to be cleared to allow the next link, which must be longer to be inserted. In any case, the length of the last two links will have to be less than the free space. 

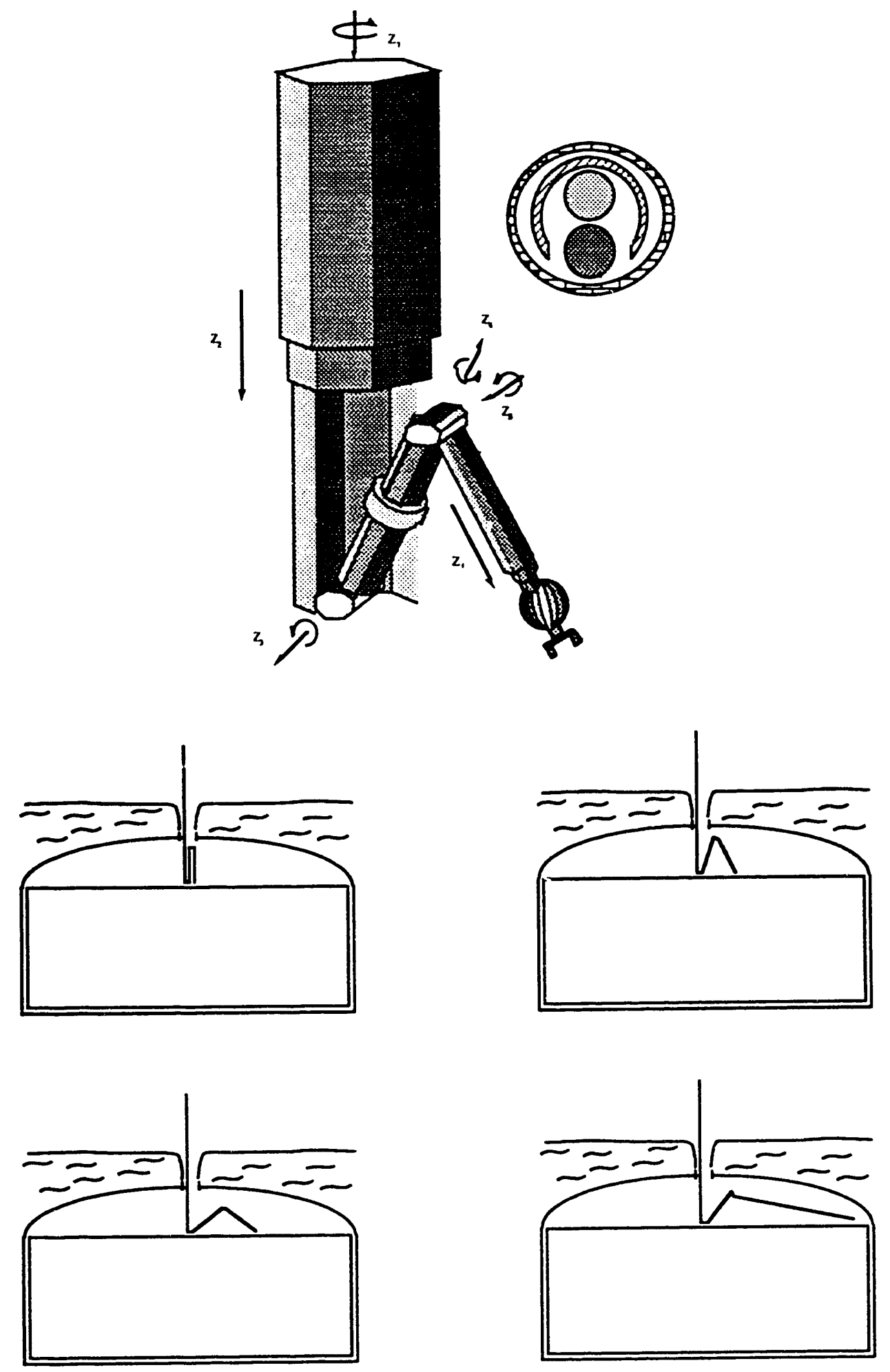

Fig. 4. Folded-entry-type (FET) long-reach manipulator deployment. 

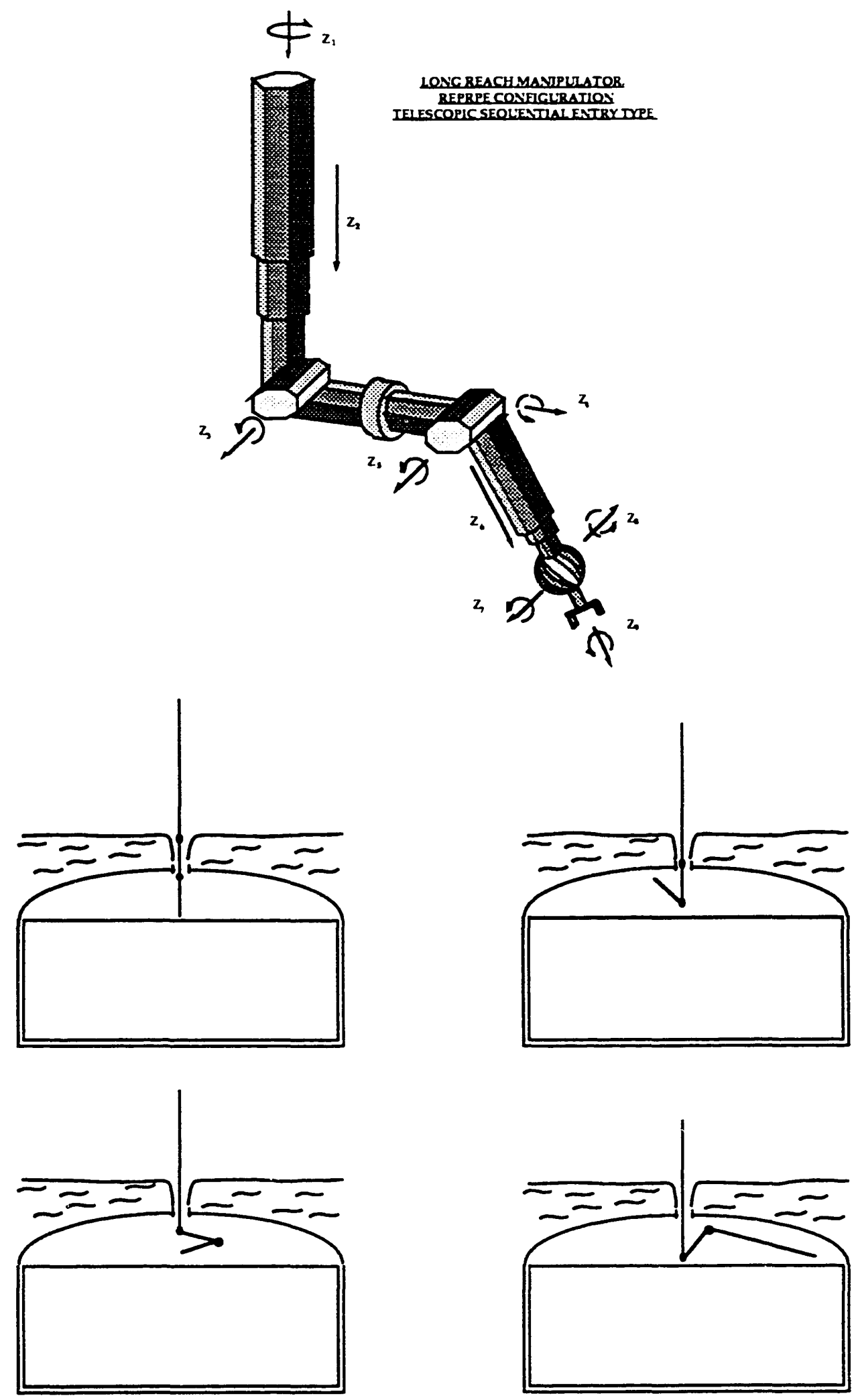

Fig. 5. Telescopic-sequential-entry-type (TSET) long-reach manipulator deployment. 

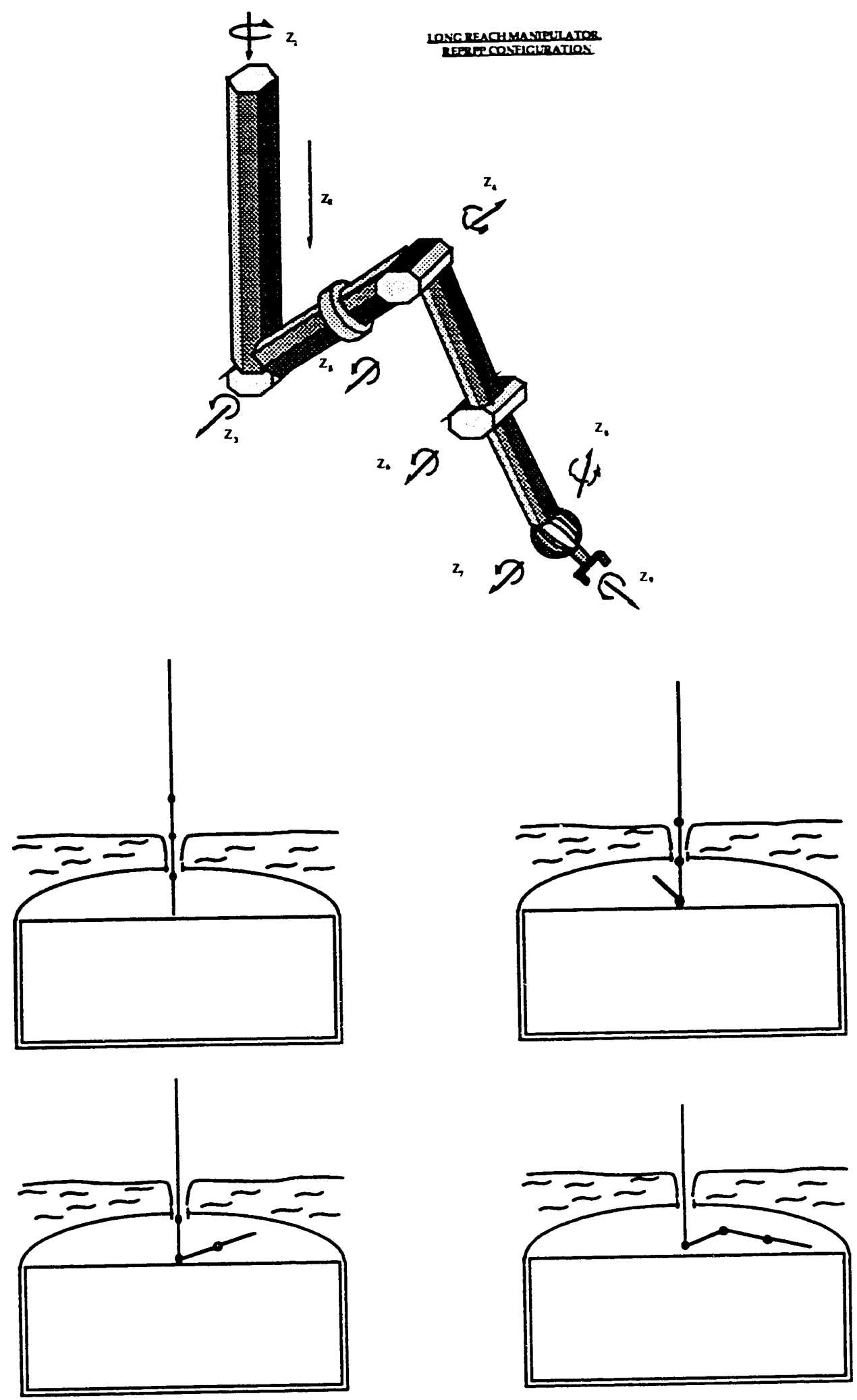

Fig. 6a. Sequential-entry-type (SET) long-reach manipulator deployment (tank diameter/clearance <3). 

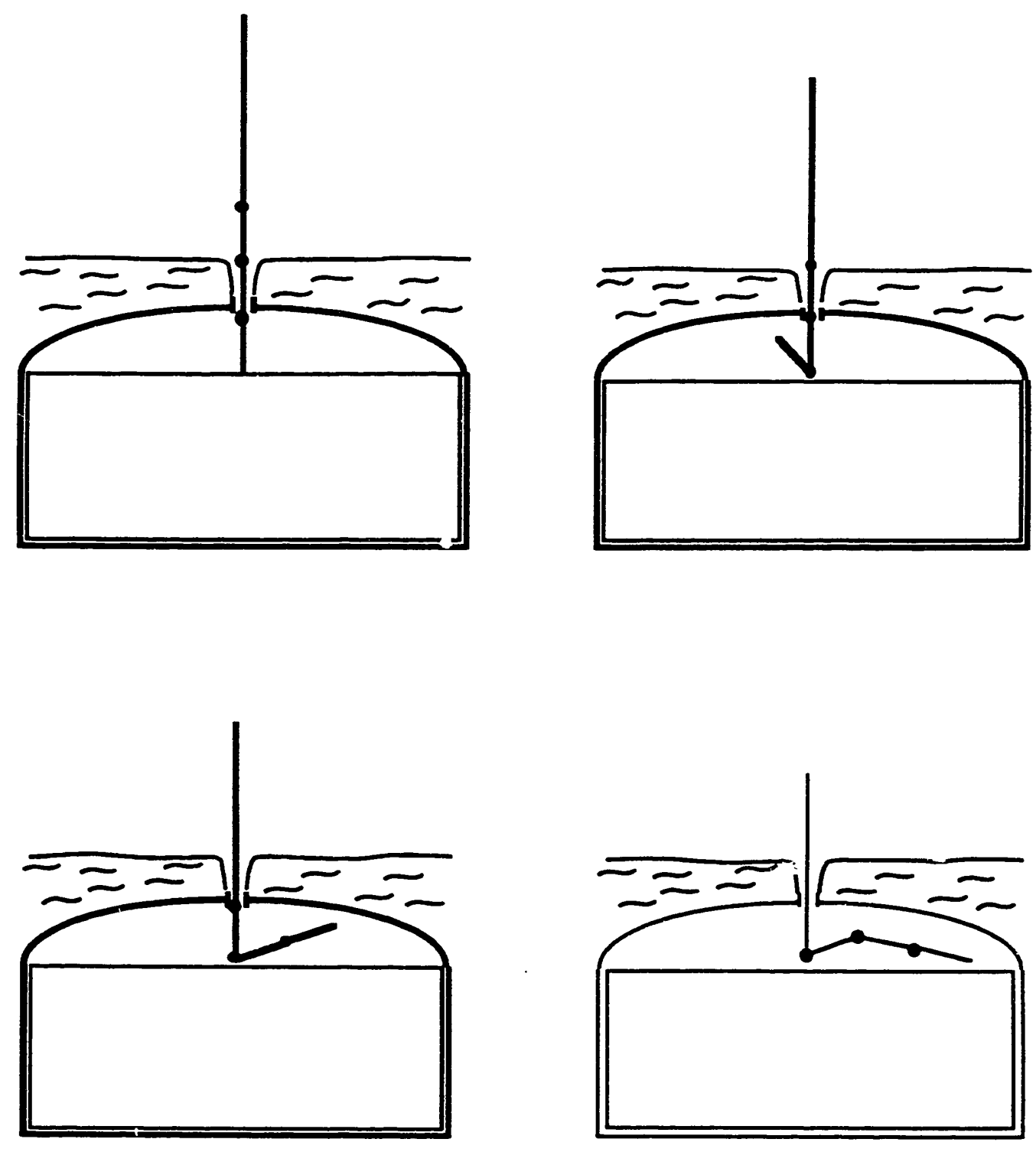

Fig. 6b. Sequential-entry-type (SET) long-reach manipulator deployment (tank diameter/clearance $>3$ ). 
between the waste and the dome. As an example, if the clearance between the waste and the dome is $12 \mathrm{ft}$ and the tank diameter is $75 \mathrm{ft}$, the last two links could be less than $12 \mathrm{ft}$ long, requiring the next to be greater than 13.5- $\mathrm{ft}$ long. Waste would need to be removed to allow insertion of the 13.5-ft link.

\subsection{ANALYSIS OF REFERENCE KINEMATIC CONFIGURATIONS}

\subsubsection{Necessity of Each Degree of Freedom}

The manipulators shown have 3 DOF of redundancy as a positioning device. Operation of the manipulator will require the solution of the resulting redundant inverse kinematics problem. A number of different procedures have been suggested for the soiution of the inver, kinematics problem for redundant manipulators. An appropriate solution for the case in study is that given by Abdel-Rahman [Abdel-Rahman 1991] which yields a simple closed-form solution for this 6-DOF positioning manipulator. In the following, the necessity of each of the 6 DOF of the proposed LRM configurations is explained in greater detail.

\subsubsection{First DOF: Rotational joint}

The volume of the workspace of the LRM is maximized when a rotational base is used. A rotational DOF is necessary at the base of the robot because of the radial symmetry of the tanks. The use of a rotational base is common to most industrial robots. Note that all of the three different configurations presented (FET, TSET, and SET) have a rotational base.

With an initial revolute joint, the workspace is a volume of revolution. As is shown in Fig. 7, the workspace of a robot with an initial rotary (roll) joint is produced by rotating the reachable area of the rest of the manipulator about the first joint axis. The area to be rotated is in a plane that contains the axis of rotation. Thus, covering the area means covering all the volume of revolution.

\subsubsection{Second DOF: Prismatic joint}

Comparing the workspace of a robot with a rotational base (see Fig. 7) with the space of the storage tank to be covered in Fig. 8, one can conclude that a translation along the $z$ axis of the workspace in Fig. 7 will cover the volume in Fig. 8 with close to minimum wasted workspace. 


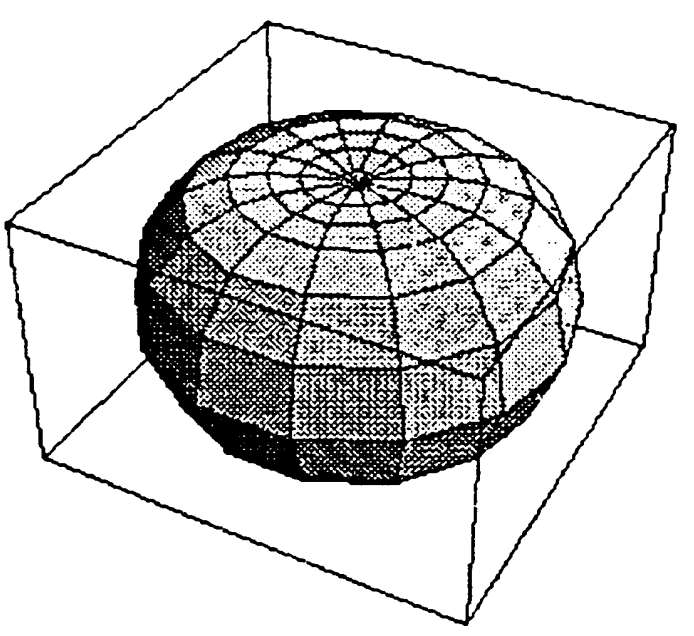

Fig. 7. Symmetric workspace of a robot with a first rotational joint.

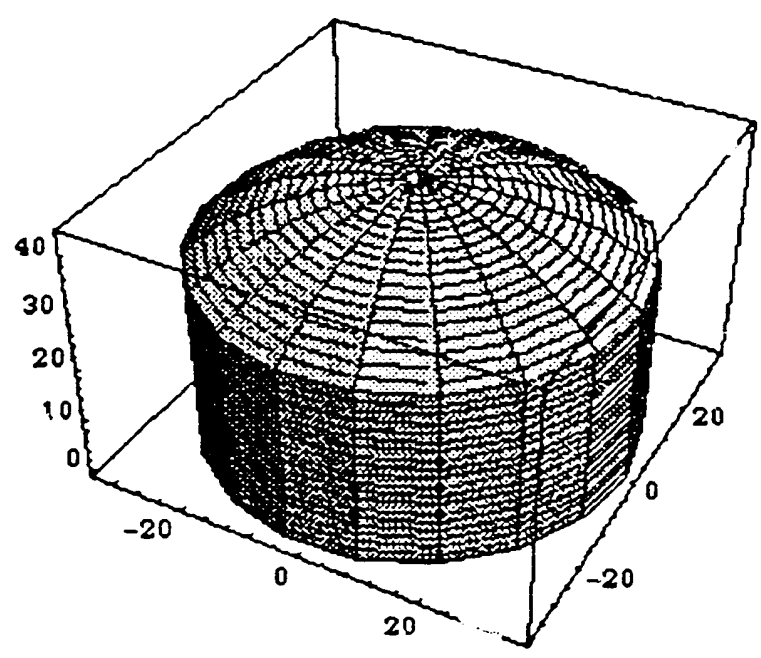

Fig. 8. Waste storage tank space to be covered.

A telescoping prismatic joint in the column minimizes the overall length of the LRM. In addition to minimizing transportation and installation problems, reducing the length of the column minimizes the effects of its deflection and vibration on the other links of this manipulator.

For the nominal tank, the column would be $52 \mathrm{ft}$ long when fully extended, which can be achieved with a three-step prismatic joint of 22-, 17-, and 13-ft consecutive exter.uions (as shown in Fig. 9). Therefore, the use of a telescoping prismatic joint in the column would reduce the overall length of the manipulator when contracted for installation and transportation by $\sim 30 \mathrm{ft}$. The penalty would be increased lateral backlash in the link.

\subsubsection{Third and fifth DOF: Rotational joints}

The two pitch rotational joints are part of the classical configuration of a rotational manipulator. They give maximum workspace coverage for minimum overall length of the manipulator [Paden 1988]. In addition, for large systems, rotational joints typically have less lateral backlash than prismatic joints.

For the FET and TSET manipulators, the two links attached to these two rotational joints have the same length, when the extension is fully contracted. This gives the maximum workspace for the same overall length [Jansen 1992] while allowing the manipulator to be deployed inside a filled tank. 


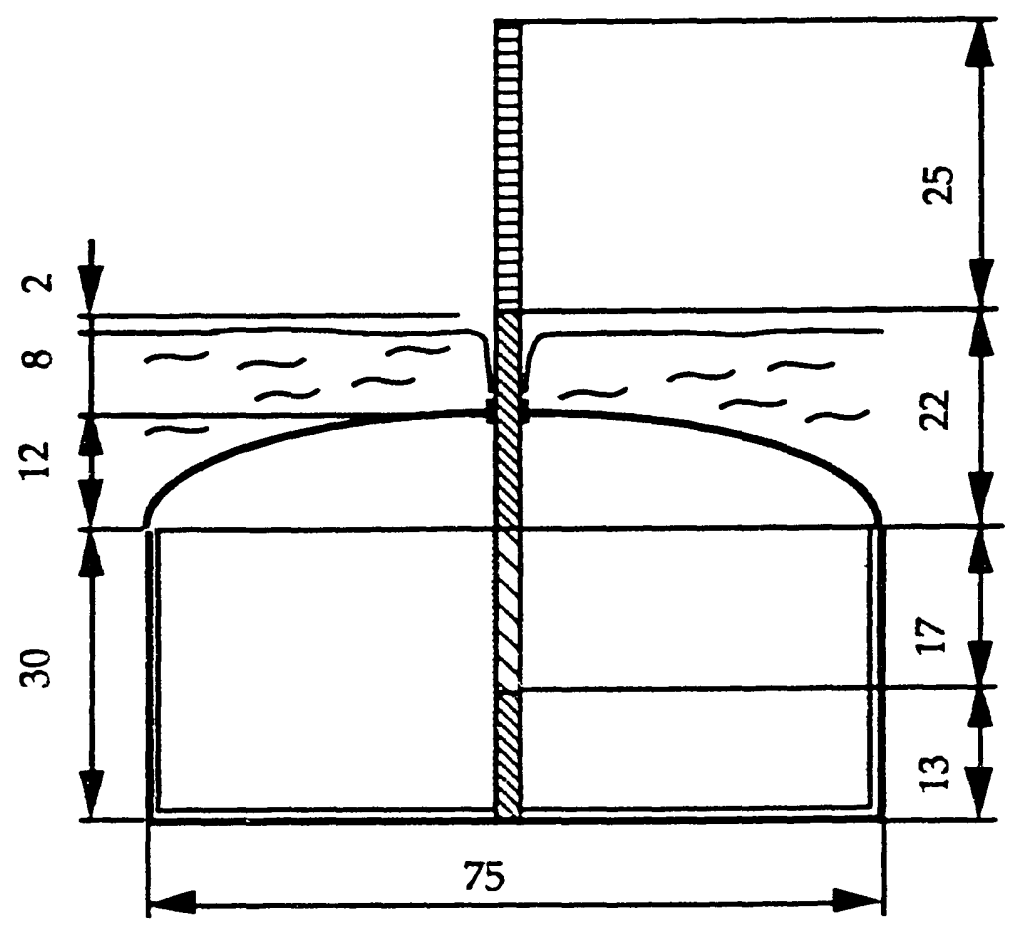

Fig. 9. Waste storage tank and telescopic column dimensions.

For the FET and TSET manipulators, the two links attached to these two rotational joints have the same length, when the extension is fully contracted. This gives the maximum workspace for the same overall length [Jansen 1992] while allowing the manipulator to be deployed inside a filled tank.

\subsubsection{Fourth DOF: Extra rotational joint}

The extra rotational DOF between the two pitches allows the LRM to work in a SCARA configuration, in an elbow up or down configuration, or in intermediate configurations. These different configurations give the LRM the ability to avoid obstacles. Also, different configurations are better for different tasks anci paths to be followed. Figures $10 \mathrm{a}$ and $10 \mathrm{~b}$ show the LRM in a SCARA configuration while taking advantage of the obstacle avoidance capabilities to reach a point on the other side of a riser.

This additional DOF also eliminates a singular configuration along the $z$-axis that the manipulator would have without it. The matrix constructed with the positional columns of the Jacobian for the TSET case, without this extra rotational DOF, was found to be of rank less than 3 when the following equation is true:

$$
a_{3} \cos \Theta_{3}+d_{5} \sin \left(\Theta_{3}+\Theta_{4}\right)=0
$$




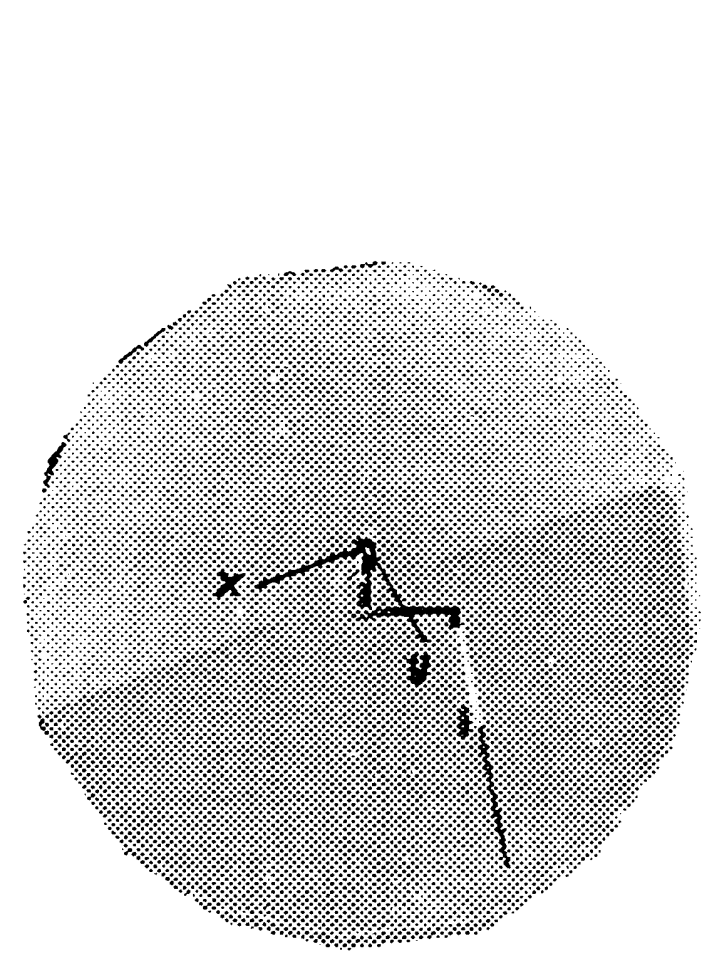

Fig. 10a. LRM in a SCARA configuration avoiding an obstacle (top view).

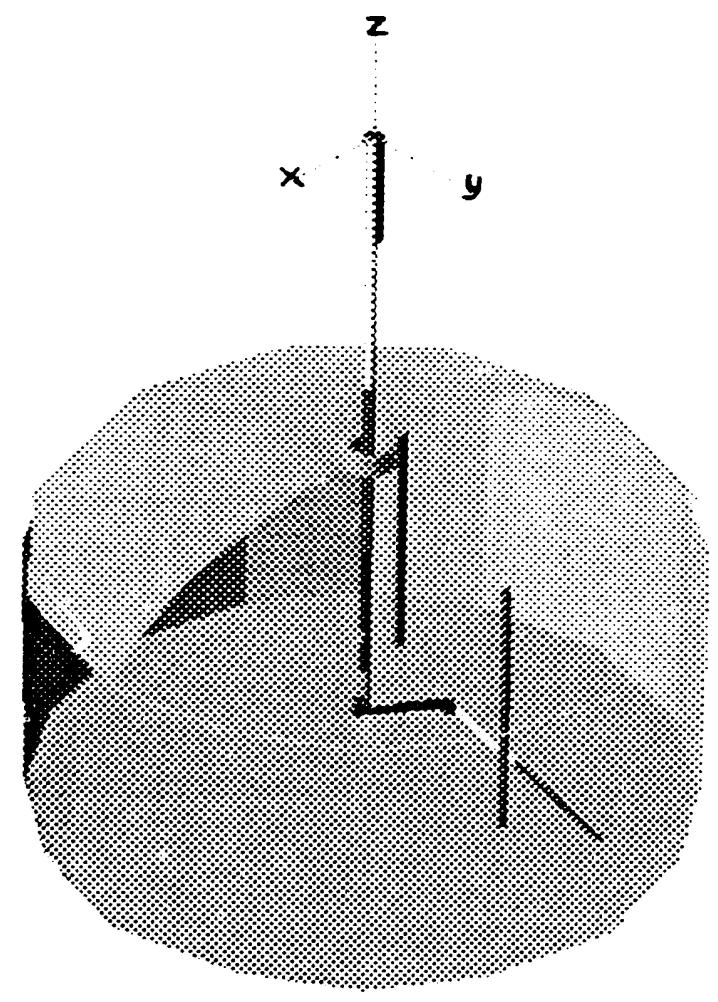

Fig. 10b. LRM in a SCARA configuration avoiding an obstacle (isometric view).

This means that when the end of the manipulator is located along the axis of the first column, the manipulator is in a singular configuration. At this specific configuration and points close to it, the manipulator cannot move along the direction orthogonal to the plane constructed with the column and the two last links. When adding the fourth rotational DOF, this singularity is eliminated.

A consequence of the use of this rotational DOF is an improvement of the connectivity of the workspace of the manipulator [Wenger 1990]. If this DOF were not included, then the second pitch joint (fifth DOF) would have to go through the position in which the two links are aligned to cover all the workspace of the tank. This would affect the well-connected workspace property that characterizes the ability of the manipulator to move between any two points in its workspace without changing its configuration from elbow up to down or vice versa.

The redundancy provided by this additional DOF would allow orientation of the links and joints to maximize the ability to damp vibration, reduce the maximum deflection of the manipulator, optimize its mechanical advantage, or improve its manipulability. 
The prismatic joint allows the manipulator to be shorter when totally retracted. This will reduce the height of the support tower by about $10 \mathrm{ft}$. This contraction also reduces the length of the beam, attenuating the static deflection and increasing the structural natural frequency of the manipulator.

The deployment of the manipulator in the free space between the waste and the dome is an important constraint for the LRM. If the first link introduced is shorter than the free height, then it can be used to clear some space to introduce the next link. If the first link is longer than the free height, then some external device would be needed to clear a hole in the waste. If a rotational joint is used for the last DOF, then, depending on the tank diameter to free height ratio, the third (and/or possibly the second) link to be introduced may have to be longer than the free height. The advantage of using a prismatic joint at the end of the manipulator is that it always allows the third link to be shorter than the free height, which means that waste would not have to be removed from a full tank before fully deploying the LRM.

The use of a telescopic final link (prismatic joint) rather than a rotational joint will reduce the total compressed length of the manipulator by $\sim 16 \mathrm{ft}$.

\subsubsection{Tower height summary}

Table 1 lists the approximate tower height required for each of the configurations considered with and without a telescopic column. As noted above, the penalty associated with the telescoping joints is potential lateral backlash. As illustrated in the table, tower heights vary from 25 to $90 \mathrm{ft}$ for the various combinations of column type and manipulator type.

\subsubsection{Workspace Coverage}

Workspace coverage is one of the most important specifications for the LRM. Full coverage of the tank is required. In this section a complete coverage of the space defined by the tank is shown to be obtained for each of the three cases in study.

The following plots were obtained for the workspace of each manipulator configuration on a vertical plane that includes the axis of the column of the manipulator. The three-dimensional workspace is generated by rotating this surface around the axis of the column. To find the workspace, some assumptions had to be made for the range of movement of the joints that were taken from industrial robots and crane catalogs. In all the cases the first prismatic column was used as a discrete DOF using only two discrete positions for the shoulder, with respect to the center of the tank shown in Figs. 11 through 13. The extra roll, with a range of at least $180^{\circ}$, was also added to the configuration of all the cases to create the plots. 
Table 1. Approximate tower height for various manipulator types.

\begin{tabular}{ccc}
\hline \multicolumn{2}{c}{ Column type } \\
Manipulator type & $\begin{array}{c}\text { Rigid } \\
\text { column } \\
(\mathrm{ft})\end{array}$ & $\begin{array}{c}\text { Telescopic } \\
\text { column } \\
(\mathrm{ft})\end{array}$ \\
FET & 52 & 25 \\
TSET & 74 & 47 \\
SET & 90 & 63 \\
\hline
\end{tabular}

\subsubsection{Failure Recovery}

A key design specification for the LRM should be the possibility of recovery from any single failure. For example, if an actuator or power failure occurs, it must be possible to extract the manipulator from the tank for service. This can be accomplished by various means.

A common approach is to use double actuators with a differential gear connection for each joint. This will provide driveability by one actuator even though the other was completely stopped. Not only is it necessary to extract the LRM from the tank but also to do so without touching the walls or the entrance.

It could be supposed that if the LRM entered straight into the tank, it could be withdrawn in the same way for the TSET and SET configurations. This is true as long as the links do not interact with the environment. If the tank were empty and there were a power failure, the brakes of the manipulator should stop it wherever it was, and then, releasing them slowly, the links should fall down by gravity providing a vertical orientation, which would allow them to be withdrawn. In the event that the tank had some waste in it, some links could interact with this waste, not allowing the link being extracted to be totally vertical. Because of the potential that links of the TSET and SET configurations could snag on the waste or in-tank hardware, additional precautions should be considered. 


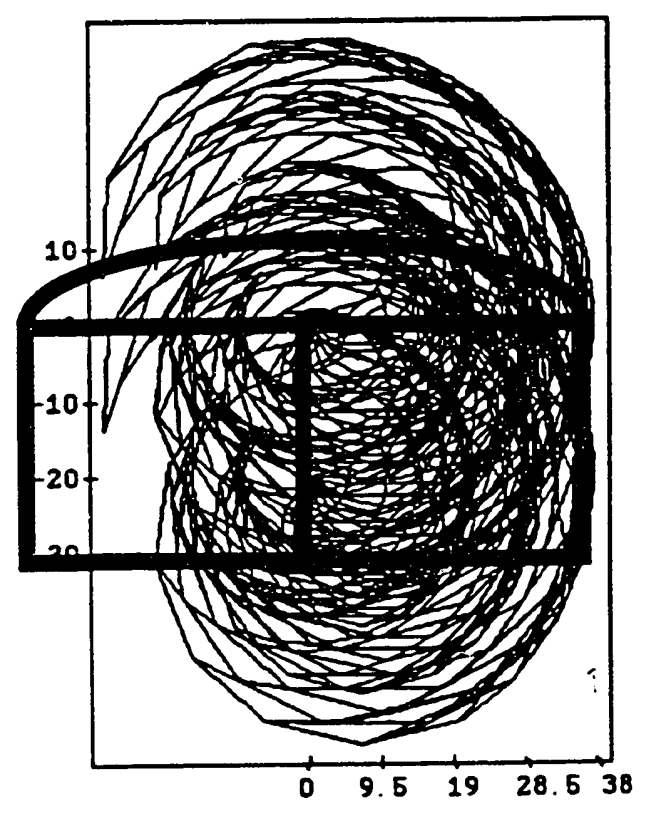

Fig. 11. Workspace of the FET case when $L 2=11 \mathrm{ft}$, $L 3$ varies from 11 to $27 \mathrm{ft}$, shoulder angle goes from $-50^{\circ}$ to $90^{\circ}$, and elbow angle from $-180^{\circ}$ to $-40^{\circ}\left(-180^{\circ}\right.$ to $100^{\circ}$ taking into account the extra roll effect ).

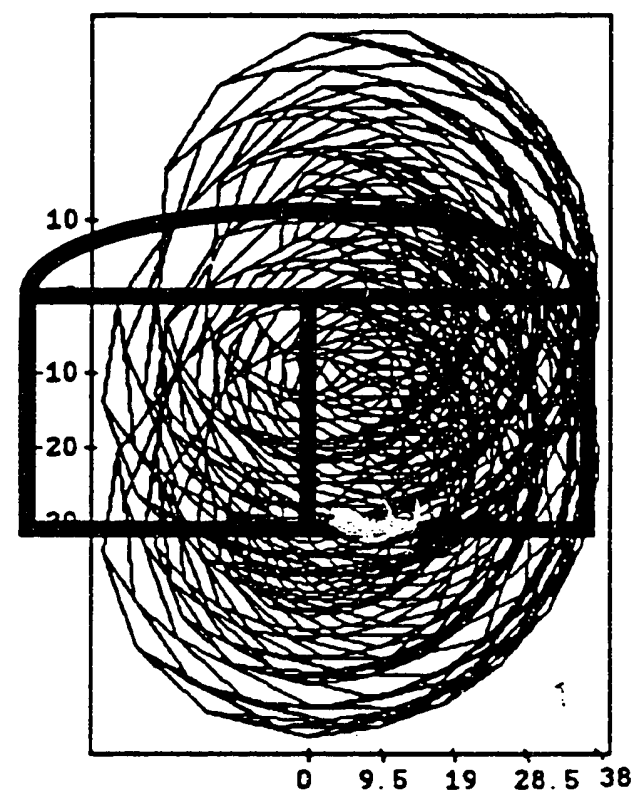

Fig. 12. Workspace of the TSET case when $\mathrm{L} 2=11 \mathrm{ft}$, $\mathrm{L} 3$ varies from 11 to $27 \mathrm{ft}$, shoulder angle goes from $-90^{\circ}$ to $50^{\circ}$, and elbow angle from $-140^{\circ}$ to $0^{\circ}\left(-140^{\circ}\right.$ to $140^{\circ}$ with the extra roll). 


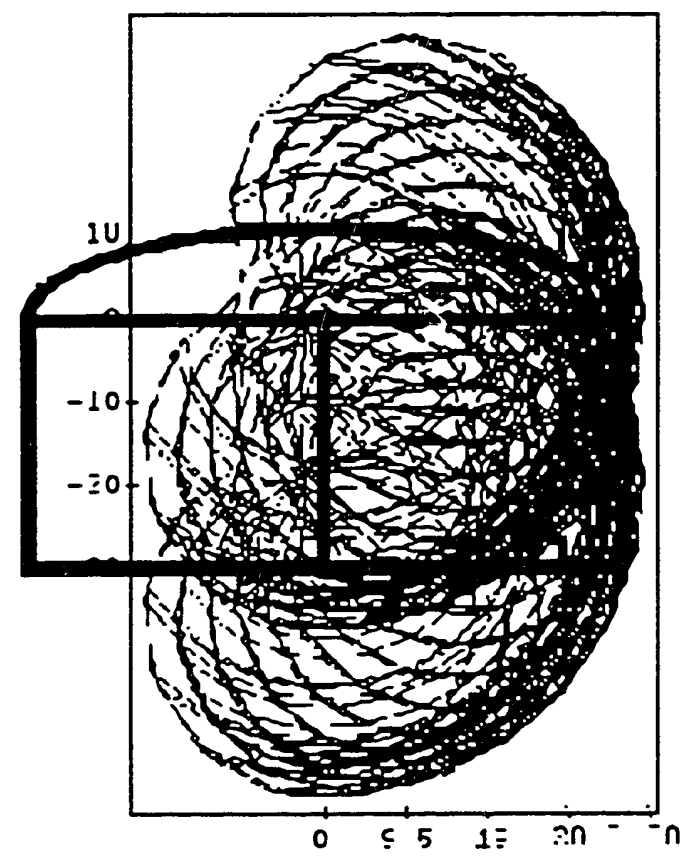

Fig. 13. Workspace of the SET case when $L 2=16 \mathrm{ft}$, L3 $=\mathrm{L4}=11 \mathrm{ft}$, shoulder angle goes from $-90^{\circ}$ to $50^{\circ}$, elbow angle from $-140^{\circ}$ to $0^{\circ}\left(-140^{\circ}\right.$ to $140^{\circ}$ with the extra roll), and the last pitch angle from $-70^{\circ}$ to $70^{\circ}$.

On the other hand, the FET configuration entered folded and could be folded from outside with minimal interaction with the environment using a simple cable through the prismatic column. The FET case appears to be the most appropriate for failure recovery, even though it would likely have worse vibration and deflection.

\subsection{SUMMARY OF ADVANTAGES OF THE ADDITIONAL ROLL}

While the extra roll DOF added between the two pitches in all three cases studied adds complexity, it has the following important advantages:

1. Singularity elimination. The singularity that all three cases have when the end-point is along the axes determined by the column is eliminated when this DOF is added.

2. Obstacle avoidance. This DOF is the one that gives the LRM obstacle avoidance capability. 
3. Reduction of the large range of motion of the second pitch. The range of motion of the second pitch should be at least from $-140^{\circ}$ to $140^{\circ}$ to cover all of the workspace. This range is only attainable with a rotary actuator or with a dynamic movement through the singular configuration (adjacent links in a straight line), as was previously suggested [Jansen 1992]. The addition of the extra roll allows the same virtual range of motion of the second pitch with a real range of motion from $-140^{\circ}$ to $0^{\circ}$ degrees. This new range is attainable with a linear actuator, which may be stronger, smaller, and have less backlash and friction due to gear reduction.

4. SCARA configuration. Without the roll, the LRM must always work in an elbow (up or down) configuration. With it, the manipulator can also work in a SCARA (horizontal) configuration or with the plane of the last links at an angle between vertical and horizontal. A SCARA configuration is better for some tasks than an elbow configuration. For higher speeds, the SCARA is better since the payload and weight of the beam will be mostly supported by the joints rather than the actuators. However, heavy payloads produce twisting of links that may not be controllable in a SCARA configuration. If the effect of vibration in that direction is combined, then it is better to use an elbow configuration.

5. Vibration damping. The mixed configurations between elbow and SCARA will allow the LRM to be configured to better control the vibration in any direction. The joint axes could be positioned such that the actuators control the vibration in the direction they are produced or absorb energy while maintaining the position of the end-point of the LRM.

6. Reaching the top of the tank. This extra DOF allows the LRM to reach the top of the tank before any waste is removed, while restricting the range of motion of the pitch DOF to allow linear actuators. This provides the capability to reach risers that have not been previously removed or to acquire a tool or an air transfer line to initiate waste retrieval procedures. 


\section{PARAMETRIC STUDY OF LONG-REACH MANIPULATOR DESIGNS}

To suggest appropriate structural design specifications of the LRM, a parametric design study was performed to demonstrate trends of the manipulator structural characteristics for various constraint conditions. The dimensions of a typical waste storage tank shown in Fig. 1 are used as nominal conditions. A computer program was developed to optimize the dimensions of each of the links for various tank diameters, entrance port diameters, payloads, and deflection design criteria. The weight, static deflection, and natural frequency are estimated on the basis of that design. The design program optimizes the size and weight of each link to satisfy constraint conditions using discrete link thicknesses that are commonly available for fabrication.

\subsection{CONSTRAINT PARAMETERS}

Structural design parameters will depend on the following constraints: the entrance hole diameter, the tank radius, the tank depth from the ground to the bottom, the dome clearance of the tank, the payload with its dynamic characteristics, a strength design criteria, a static deflection allowance, the minimum inner size of each link, and the material.

Primarily, tank size, the dome clearance of the tank, and available tower height determine the kinematic design for the type, configuration, and link lengths of the manipulator. Secondly, the payload and design criteria for strength and static deflection determine the size and thickness of the beam. The entrance hole diameter limits the maximum characteristic diameters of the links. If a link's outer dimension is over the limit due to the entrance hole or under the minimum inner size, it is adjusted by changing the link thickness parameters.

\subsection{ASSUMPTIONS FOR THE MANIPULATOR DESIGN}

Several basic assumptions were made which significantly affect the design of an LRM for waste tank remediation. These are discussed in the following paragraphs.

In this study, the waste level is assumed to be at almost $100 \%$ of the tank capacity. If the tank is full up to the top of the side wall steel liner, the manipulator has to have a working configuration in the dome clearance space after it is inserted through the entrancs hole. The dome clearance height, the depth of the waste, and the diameter of the tank will determine the link lengths of the manipulator. 


\subsubsection{Waste Level}

In this study, the waste level is assumed to be at almost $100 \%$ of the tank capacity. If the tank is full up to the top of the side wall steel liner, the manipulator has to have a working configuration in the dome clearance space after it is inserted through the entrance hole. The dome clearance height, the depth of the waste, and the diameter of the tank will determine the link lengths of the manipulator.

\subsubsection{Entrance Port Location and Diameter}

The entrance port is assumed to be at the center of the dome. Even though some underground storage tanks have an off-centered large entrance port, this study only considered ports at the center of the dome. Entrance port diameters are assumed to vary between 24 and 42 in. The analysis preferred here can be extended to different specific geometries in a straightforward manner.

\subsubsection{Actuator Power Capacity and Weight}

The actuator weight is estimated from the required power capacity using rough linearized weight and power relations of commercially available products.

\subsubsection{Deflection}

Only deflections due to bending moment are considered. If the roll DOF between two pitch DOF is employed, torsional deflections should be considered when the plane of the last links is not vertical.

\subsection{SHAPE OF THE LINK STRUCTURE}

A circular link would have the highest inertia-to-area ratio for the circular entrance hole restriction [Jansen 1992]. However, circular columns are very difficult to manufacture. Hexagonal-type structures give relatively high inertiato-area ratios, are easy to build, and are good for telescopic extensions. For the folded-entry-type manipulator for which two links are folded inside the column, a square cross section gives a higher inertia-to-area ratio than a circular cross section and is also easier to build. A hexagonal cross section was chosen for the column; a square cross section was chosen for the other links.

\subsection{OPTIMAL DESIGN OF THE MANIPULATOR LINKS}

\subsubsection{Allowable Link Characteristic Diameter}

For an SET manipulator, the minimum size of each link is limited by the diameter of the extension cylinder, hydraulic hoses, and supply lines for end-effector tools. In this analysis, the minimum sizes of the links were assumed to be 10 in. for the lower link(s), 11.5 in. for the upper link, and $15 \mathrm{in}$. for the 
column. The maximum size of the column link is assumed to be limited to $80 \%$ of the entrance hole diameter to allow some clearance for the possibility of including a manipulator boot in the final design.

For a folded-type manipulator, the minimum sizes of the links are assumed to be the same as for the sequential-entry types 10 in. for the lower link, and 11.5 in. for the upper link. The minimum size of the column should be greater than the sum of the upper link and lower link dimensions to be folded inside the column. So, the minimum diameter of the column is assumed to be $110 \%$ of the sum of the two. The maximum diameter of the column is assumed to be $80 \%$ of the entrance hole diameter. The maximum upper and lower link characteristic diameters are limited to $40 \%$ of the column characteristic diameter to allow them to be folded inside the column.

\subsubsection{Structural Strength Criteria}

The structural strength design criteria with a safety factor of 2.5 were applied at the maximum stress point to satisfy the working requirements of 260,000 cycles ( $1 \mathrm{cycle} / \mathrm{min} \times 60 \mathrm{~min} \times 24 \mathrm{hrs} \times 180$ days) during 6 months.

\subsubsection{Static Deflection Criteria}

The static deflection criteria are very important. In most cases, the static deflection requirement is more strict than the strength design criteria. The size and thickness of a link are mainly determined by the deflection criteria. Static deflection is also closely related to natural frequency. It has been shown that a bandwidth of about one half of the fundamental natural frequency yields maximum damping for a manipulator joint controller [Book 1975]. Therefore, the specification of the static deflection can be considered as the criterion for the bandwidth of the manipulator system.

However, it is not easy to directly apply the end-effector static deflection criteria individually to the design of each link. The best way seems to be to optimize the size and thickriess of all links at the same time to minimize the weight while satisfying the design criteria and constraint conditions. To give more strict deflection constraints for longer links, a certain amount of static deflection per unit length $(0.0018-0.0075 \mathrm{in}$./ in. with a nominal value of 0.0028 in./in.) at the maximum payload has been used for the design criteria. That usually allows a static deflection at the end-effector between 4 and 12 in.

\subsubsection{Optimization of the Structure Size}

The optimization of the thickness with continuous numbers is unrealistic for actual manufacturing. Results will show that manufacturing using thicknesses that are not available commercially will be very costly. The potential for local buckling and stress concentration will limit the minimum wall thickness. Therefore, the size and the thickness of the beam have been optimized with 
discrete values of thickness by the static deflection and stress criteria. The calculated size of the beam was also tested and reoptimized to satisfy restrictions that come from the entrance hole diameter and type of the manipulator.

\subsection{PARAMETRIC DESIGN ANALYSIS PROCEDURES}

A parametric design analysis procedure was developed and implemented using Mathematica [Wolfram 1988]. Figure 14 depicts a flowchart of the procedure.

First, assuming the range of input variables, which are the constraint parameters such as tank size, eritrance hole diameter, and payload, the type of the manipulator, the number of links, the shape of the links, and the material are specified.

Second, the parameters to be varied and those to be fixed are chosen, and the iterative procedure for the structural design is initiated. The moment distribution and reaction force of the link with payload from the end link to the column are calculated. The link size is optimized to minimize the weight while satisfying the strength design criteria, static deflection design criteria, and other constraint conditions with a discretized wall thickness (a minimum wall thickness of $1 / 8$ in. and incremental increases in thickness of $1 / 16 \mathrm{in}$. were assumed). After the link dimensions are calculated, the actuator weight is estimated from the link weight and payload. The structural system characteristics such as total system weight, static deflection, and the fundamental system natural frequency are then calculated. The fundamental natural frequency is approximately proportional to $1 / \sqrt{\text { static deflection }}$ [Blevins 1979]. We have confirmed that the natural frequency approximately estimated from the static deflection agrees reasonably well with the exact solution (errors are of the order of 10 to $20 \%$ ). In the parametric analysis, the approximate natural frequency results were used.

Third, after completion of the iterative procedure for the whole range of the parameters, the output parameters are plotted against the appropriate input parameters.

\subsection{ANALYSIS OF PARAMETRIC DESIGN RESULTS}

The manipulator is simplified to three parts: column, upper link, and lower link. The extensions of the column or links are assumed to be one simple column or one link to reduce calculations that would be needed for different types. Telescopic extensions were assumed to be one uniform, rigid link. Since the structural characteristics of the SET and the TSET are almost the same, only the two cases of the TSET and the FET were considered in this analysis. The weight, outer dimensional size of the link, thickness of the link, static deflection, and structural natural frequency are compared by varying payload, static deflection allowance, tank size, and entrance hole diameter. 


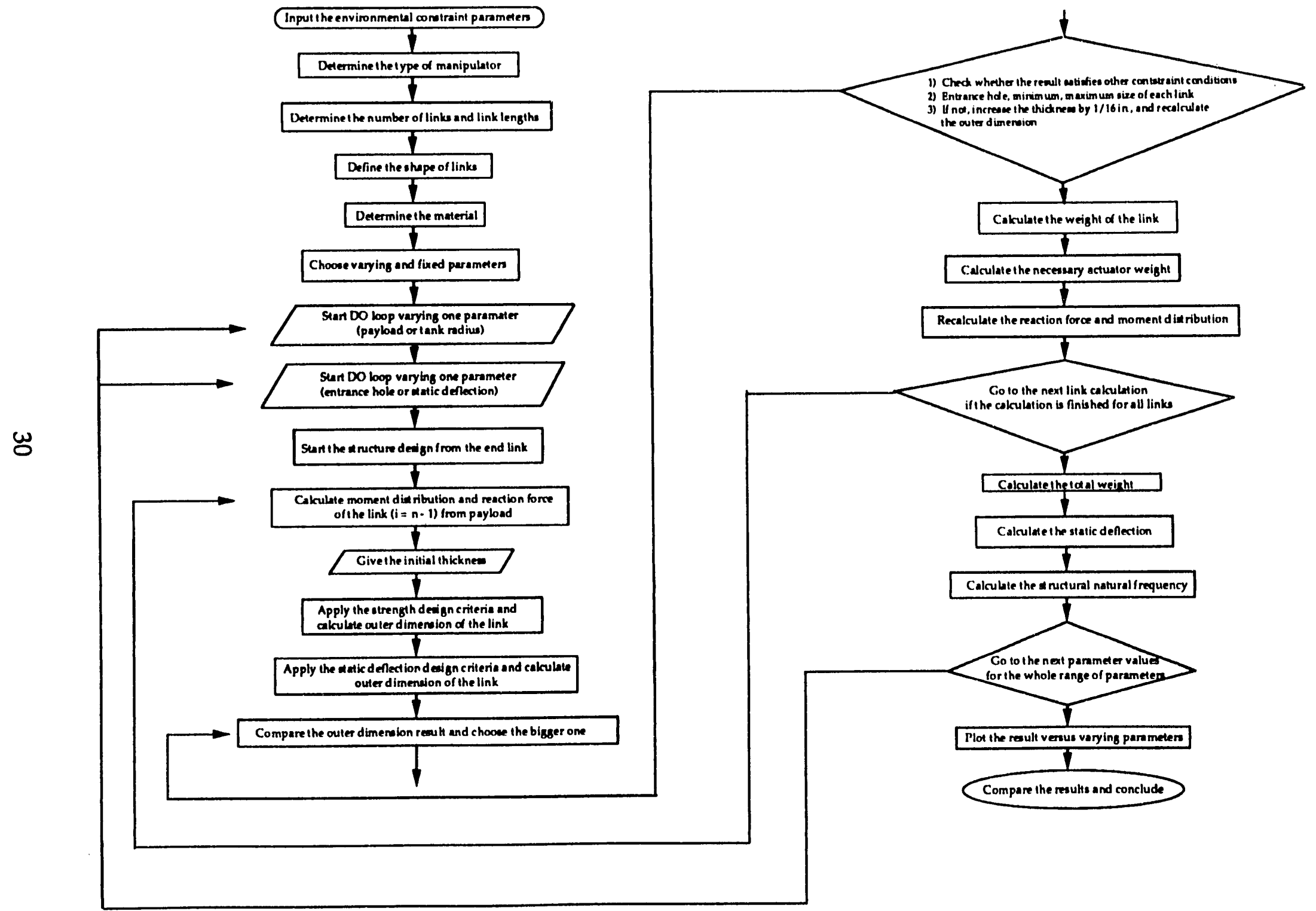

Fig. 14. Flowchart of the parametric analysis. 


\subsubsection{Case 1: Varying the Static Deflection Requirement with Different Payloads for the TSET Manipulator}

This case considers varying the static deflection requirement with different payloads for TSET manipulators. Static deflection was varied from 4 to 12 in. for payloads of 500,1000 , and $1500 \mathrm{lb}$. The diameter of the entrance port was fixed at 42 in., and the maximum column characteristic diameter size wasrestricted to $80 \%$ of the entrance port diameter. The size of the tank was fixed to have a depth from the ground to the tank bottom (the column length) of $50 \mathrm{ft}$ and a tank radius (manipulator horizontal reach) of $38 \mathrm{ft}$.

\section{Weight}

As shown in Fig. 15, the manipulator weight changes rapidly when the static deflection allowance is less than 4 in. A reasonable static deflection requirement seems to be 4 to 7 in. at the endpoint of the manipulator. For the $1500-1 b$ payload case, a static deflection of more than $9.5 \mathrm{in}$. is not allowed by the structural strength design criterion. That means that if static deflection design criterion is relatively large, the strength design criterion will determine the size and wall thickness of the manipulator.

\section{Natural frequency with maximum payload}

Because the same static deflection design requirements were applied for three different payload cases, the optimal design procedure resulted in the same natural frequency plots (see Fig. 16).

The range of the natural frequency with the maximum payload will be 1 to $2 \mathrm{~Hz}$. This result shows that a dramatic improvement in the system natural frequency cannot be easily obtained. It is reasonable to expect 1 to $1.5 \mathrm{~Hz}$ for a system fundamental natural frequency when all joints are clamped and to design the control scheme and path planning to deal with the low-frequency structure.

\section{Natural frequency without payload}

Because the structure was designed to have the same static deflection for different payloads, the structure designed for the heavier load is stiffer, and it has a higher natural frequency for no payload, as shown in Fig. 17. The range of the natural frequency without payload is 1.5 to $3 \mathrm{~Hz}$. The sharp curves of the plots are due to the discrete increase of the wall thicknesses of the column and links. 


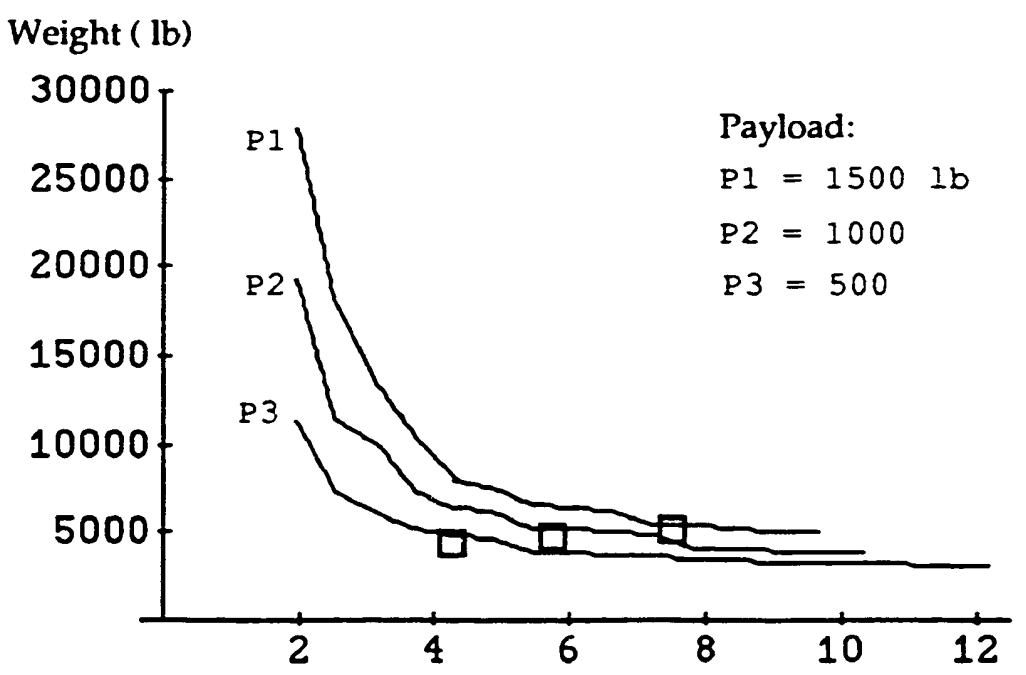

Static deflection design criteria with max payload (in.)

Fig. 15. Total weight of the manipulator.

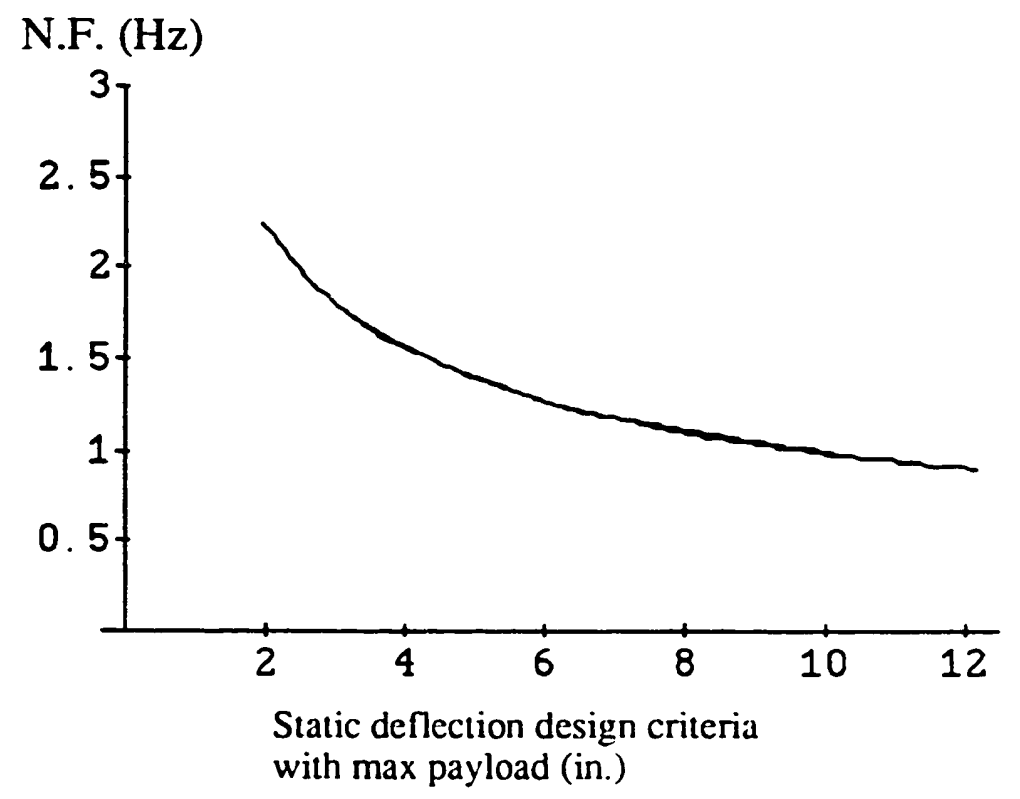

Fig. 16. Natural frequency with maximum payload. 


\section{Size of the largest link (column)}

The column diameter is limited to 33.6 in., which is $80 \%$ of the entrance hole diameter. For the $500-\mathrm{lb}$ payload case, the column size reached the maximum, and the wall thickness is increased for the static deflection requirement less than 5 in. For the 1000- and 1500-1b payload cases, the column size reached the maximum at about a 7 -in. static deflection requirement. The results are shown in Fig. 18.

\section{Stäic deflection without payload}

Figure 19 displays the static deflection, without the payload, of a structure that was designed to have the same static deflection with different payloads. It is obvious that the structure designed for the heavier load is stiffer and that it has a smaller deflection for no payload.

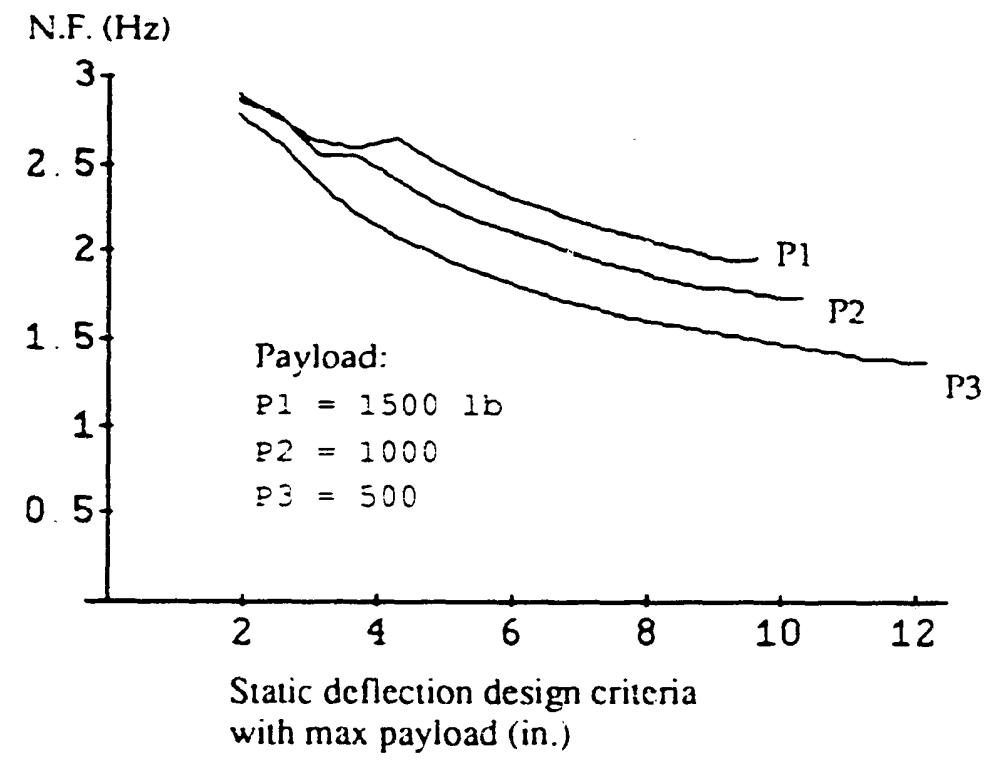

Fig. 17. Natural frequency with no payload. 


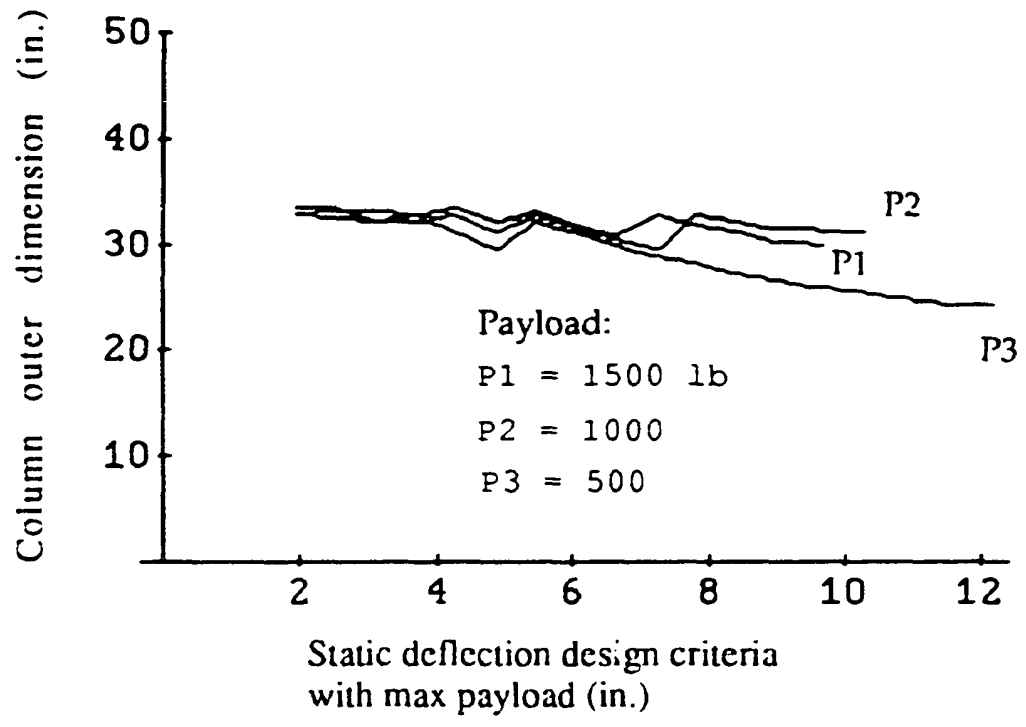

Fig. 18. Column size versus static deflection design criteria.

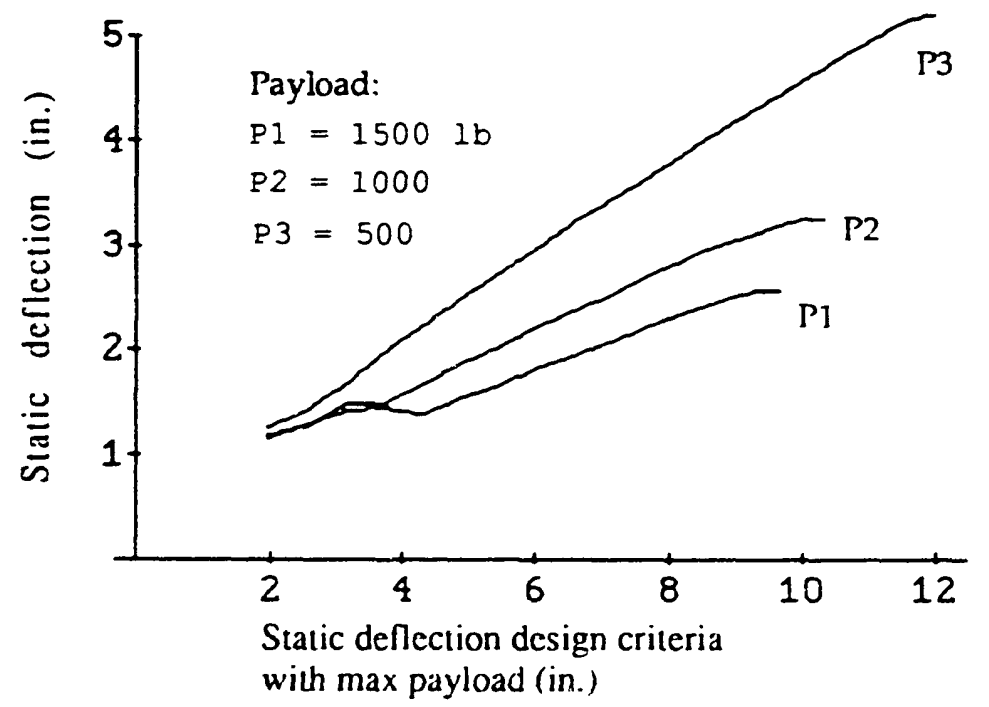

Fig. 19. No-load static deflection versus static deflection design criteria. 


\subsubsection{Case 2: Varying the Entrance Hole Diameter with Different Tank Sizes for the SET Manipulator}

In this case, tank radii of 24, 31, and $38 \mathrm{ft}$ and port diameters from 25 to $55 \mathrm{in}$. were considered. The payload was fixed to be $1000 \mathrm{lb}$ and the desired static deflection at the maximum payload was fixed to be 6 in.

\section{Weight of the manipulator}

As shown in Fig. 20, if the tank radius is smaller, then the manipulator will be lighter, and a smaller entrance hole will be acceptable because the design criteria can be satisfied by smaller size links. If the entrance hole becomes too small, the manipulator design methodology will increase the wall thickness of the links to meet the design criteria because the size of the links is very limited. A heavy manipulator will be unavoidable. If we increase the entrance hole diameter, the weight of the manipulator will be decreased to a minimum level at it will remain. The thickness has reached a minimum and the design criteria are still satisfied, so the diameter of the links does not need to be increased. Therefore, there is an acceptable range of entrance hole diameters for a specific-capacity manipulator. For a tank radius of $38 \mathrm{ft}$, a hole diameter between 35 and 45 in. will be an appropriate constraint condition.

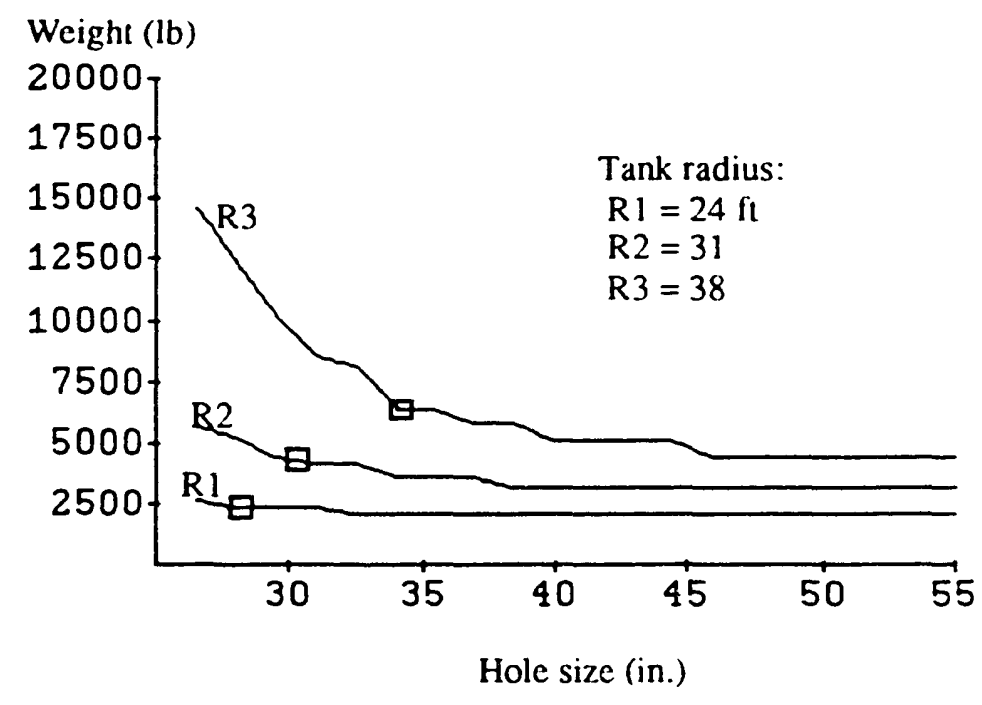

Fig. 20. Weight of the manipulator.

\section{Natural frequency}

The structural natural frequency has not been affected by the hole diameter constraint condition because static deflection requirements are usually satisfied for the range of varying parameters. The frequencies with payload (Fig. 21) are about 1.3-1.6 Hz, and the frequencies without payload are 2-3.5 $\mathrm{Hz}$ (Fig. 22). 


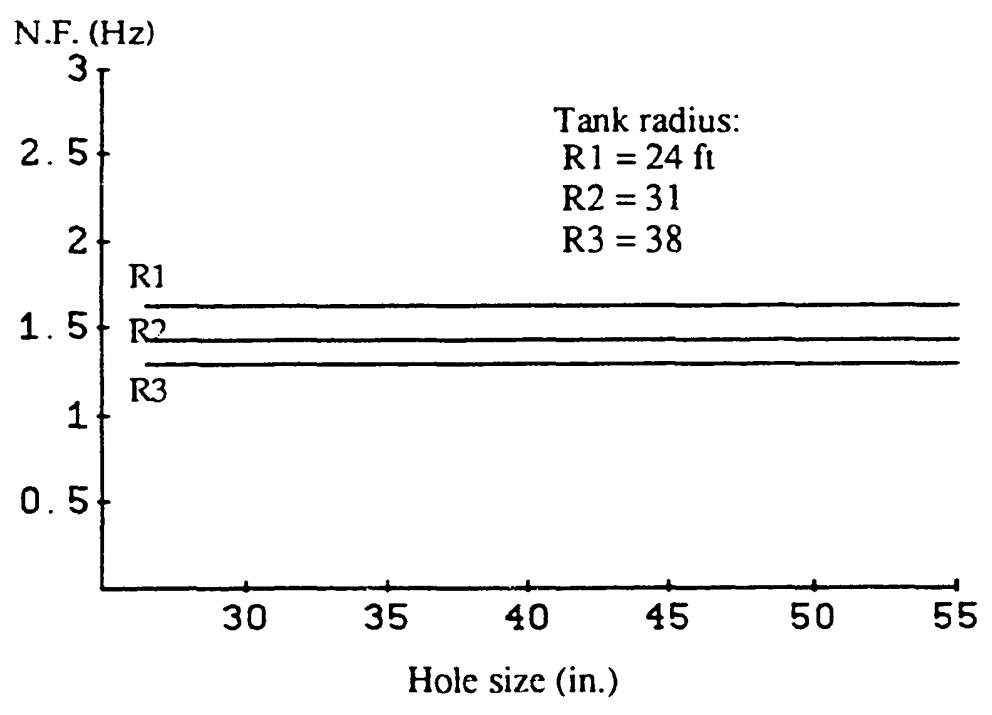

Fig. 21. Natural frequency with maximum payload.

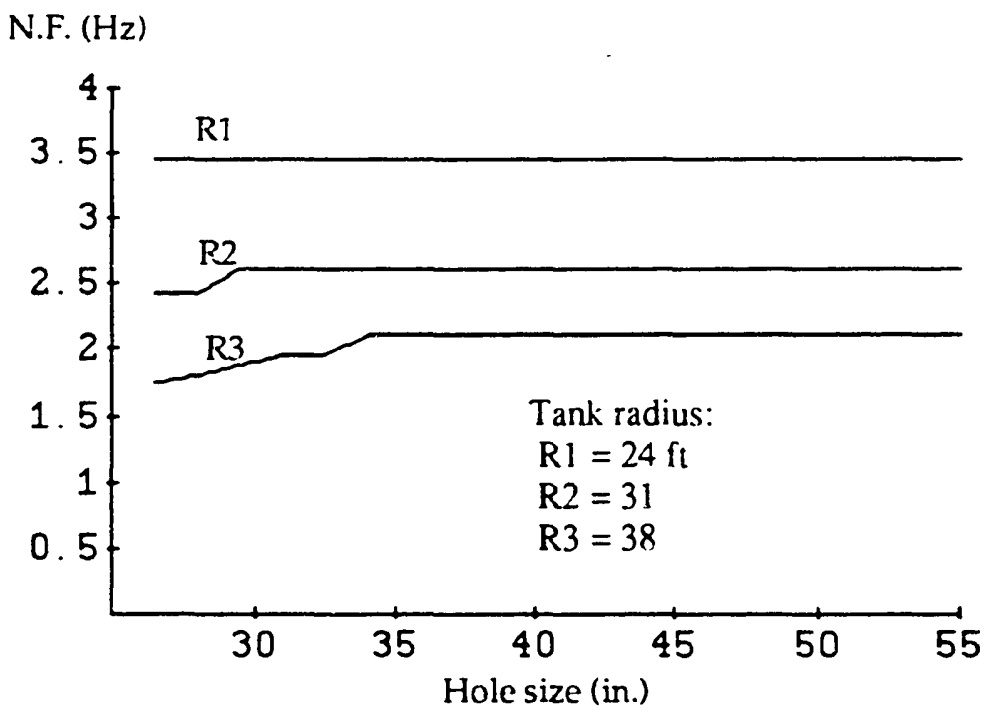

Fig. 22. Natural frequency with no payload.

\section{Size of the column}

For a manipulator with a horizontal reach of $24 \mathrm{ft}$, a 25 -in. diam hexagonal column was stiff enough so that a hole no larger than 31 in. was necessary for the given design criteria. As shown in Fig. 23, a tank radius of $31 \mathrm{ft}$ requires less than a $36-i n$. hole, and one with a radius of $38 \mathrm{ft}$ requires less than a 47 -in. hole. 


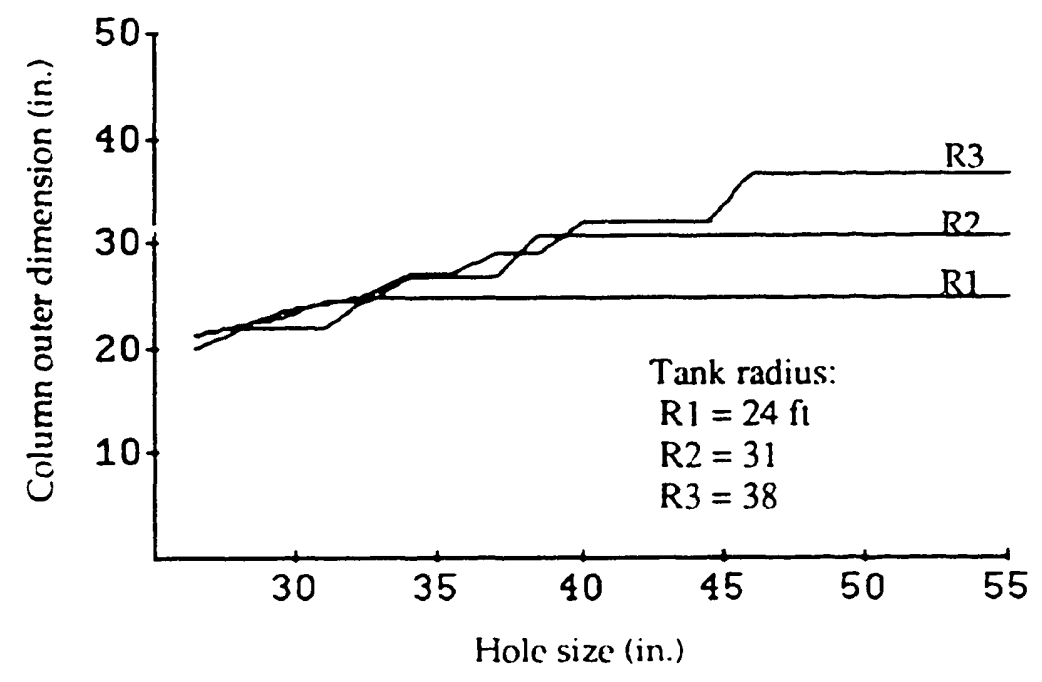

Fig. 23. Column size versus hole diameter.

\section{Static deflection}

Since the static deflection design requirement was given per unit link length, the total static deflections depend on the manipulator horizontal reach, which is related to the tank size. The static deflection with the maximum payload is essentially independent of hole diameter, as shown in Fig. 24. However, it varies with no payload, as shown in Fig. 25.

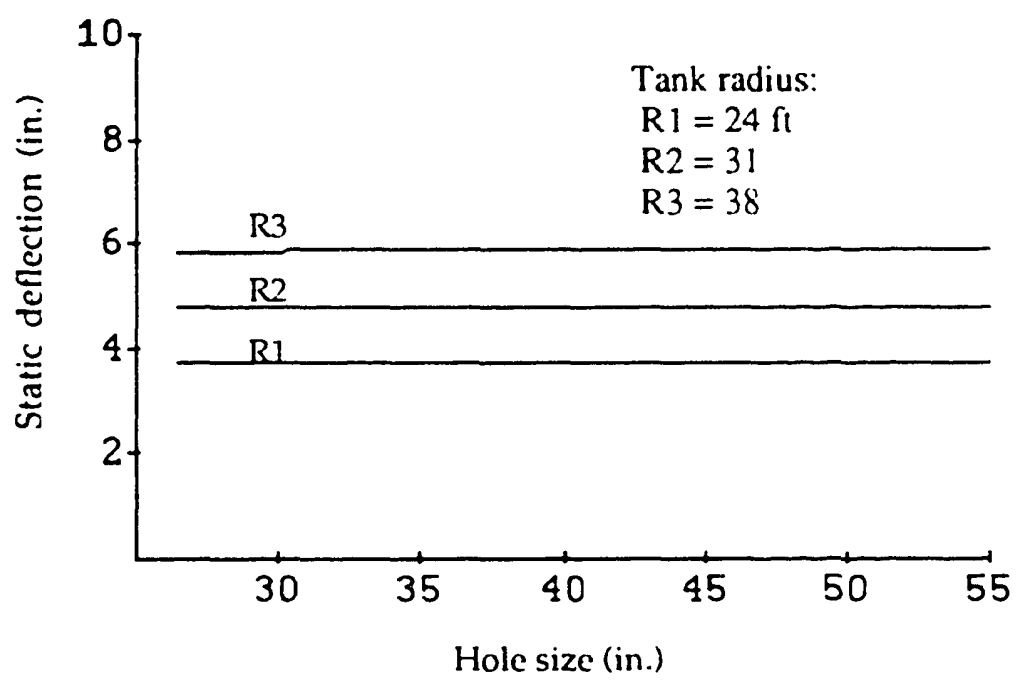

Fig. 24. Static deflection with maximum payload. 


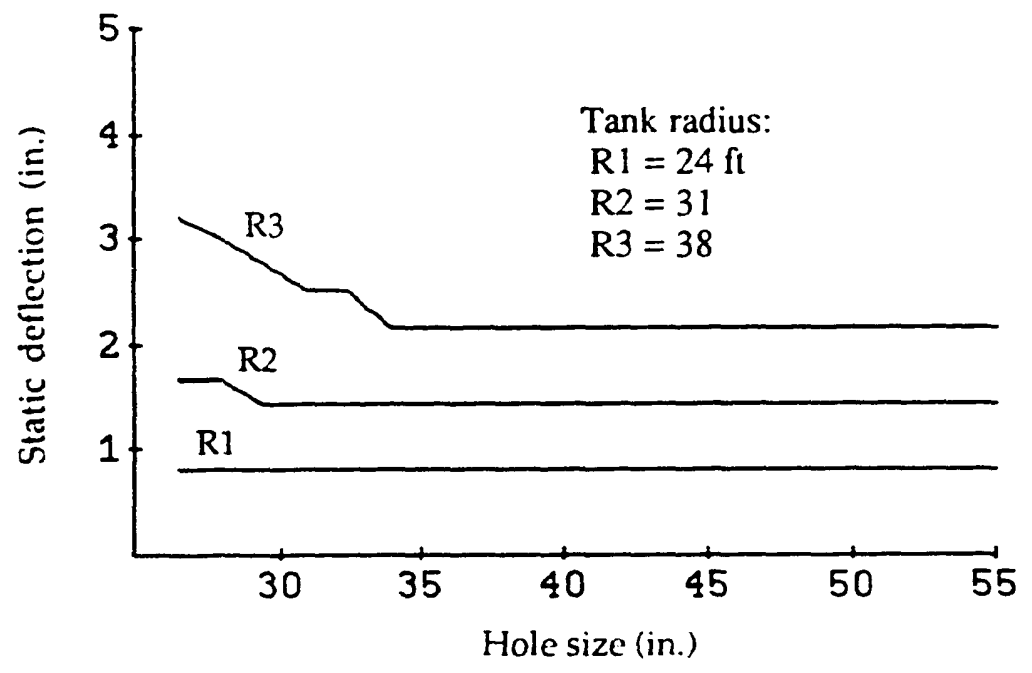

Fig. 25. Static deflection with no payload.

\subsubsection{Case 3: Varying the Static Deflection Requirement with Different Payloads for the Folded-Type Manipulator}

In this case, the static deflection is varied from 4 to 12 in., and payloads of 500,1000 , and $1500 \mathrm{lb}$ are considered. The diameter of the entrance port was fixed at 42 in., and the maximum column size was restricted to $80 \%$ of the entrance port diameter. The size of the tank was fixed to consist of a depth from the ground to the tank bottom (the column length) of $50 \mathrm{ft}$ and a tank radius (manipulator horizontal reach) of $38 \mathrm{ft}$. This case is the same as case 1 except that it is for a folded-type manipulator rather than a sequential entry manipulator.

\section{Weight}

The folded-type manipulator weight increases more rapidly than the TSET weight as the static deflection requirement decreases, as shown in Fig. 26. A reasonable static deflection requirement seems to be 6 to $8 \mathrm{in}$. for the folded type. For the 1500-lb payload case, a static deflection less than 4 in. is almost impossible. The outer size of the column is limited by the entrance hole diameter, and the inner size is limited by the size of other links that will be folded inside. Since the maximum size of the link also has to be limited by the size of the column, the folded type is suggested if relatively large static deflections are allowed. 


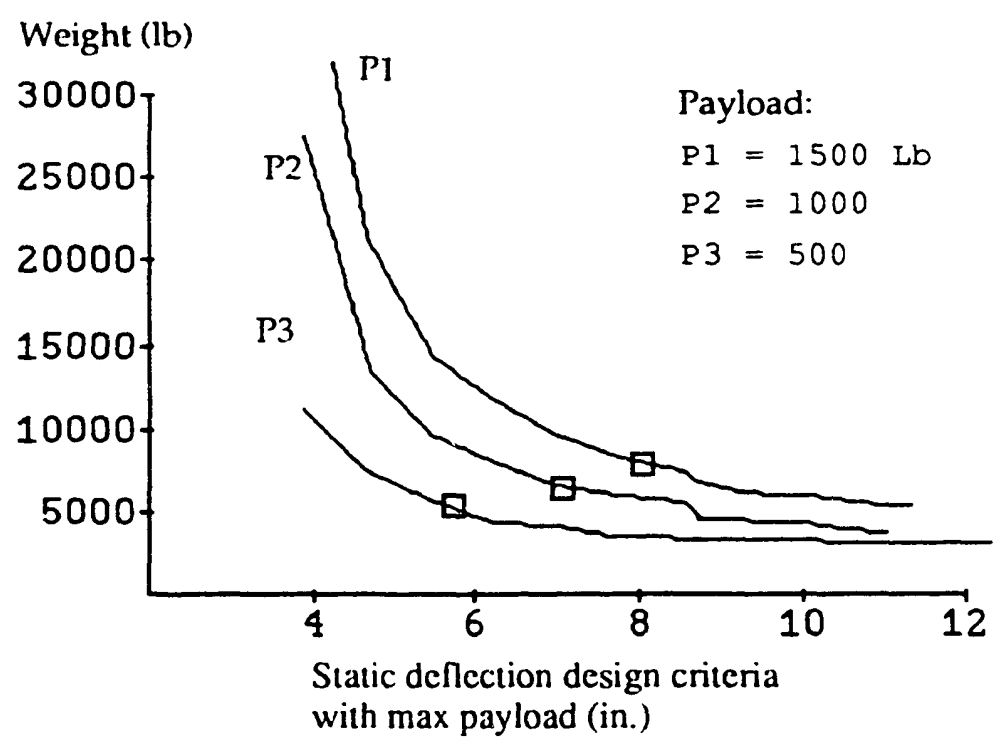

Fig. 26. Total weight of the manipulator.

\section{Natural frequency}

The range of natural frequency is about $1-1.5 \mathrm{~Hz}$ with the maximum payload and $1.5-2 \mathrm{~Hz}$ without the payload. Generally, the folded type will have larger static deflection and lower natural frequency compared to a TSET manipulator with the same weight. The plots also show that there will not be any dramatic improvement of the system natural frequency resulting from changes in the design criteria or the type of the manipulator. For the maximum payload, the optimal design procedure resulted in the same natural frequency plots (Fig. 27) for the three payloads, since the same static deflection requirements were applied. The natural frequency without payload varies as shown in Fig. 28.

\section{Size of the largest link (column)}

For a $1500-1 b$ payload, more than a 10.5-in. static deflection is not allowed by the strength design criteria. Figure 29 shows that less than a 4.5-in. deflection requirement makes the characteristic diameter of the column larger than $80 \%$ of the entrance hole diameter, even though it did not exceed the entrance hole diameter (42 in.). The range of the static deflection design criteria for heavy loads is relatively limited for the folded type. 


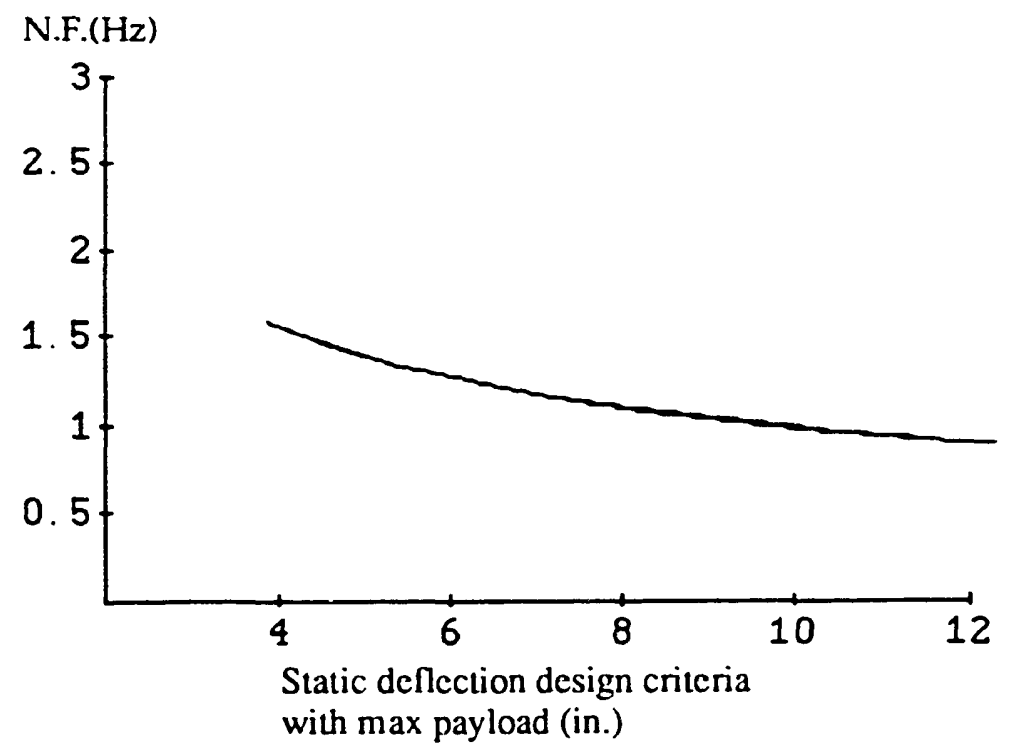

Fig. 27. Natural frequency with maximum payload.

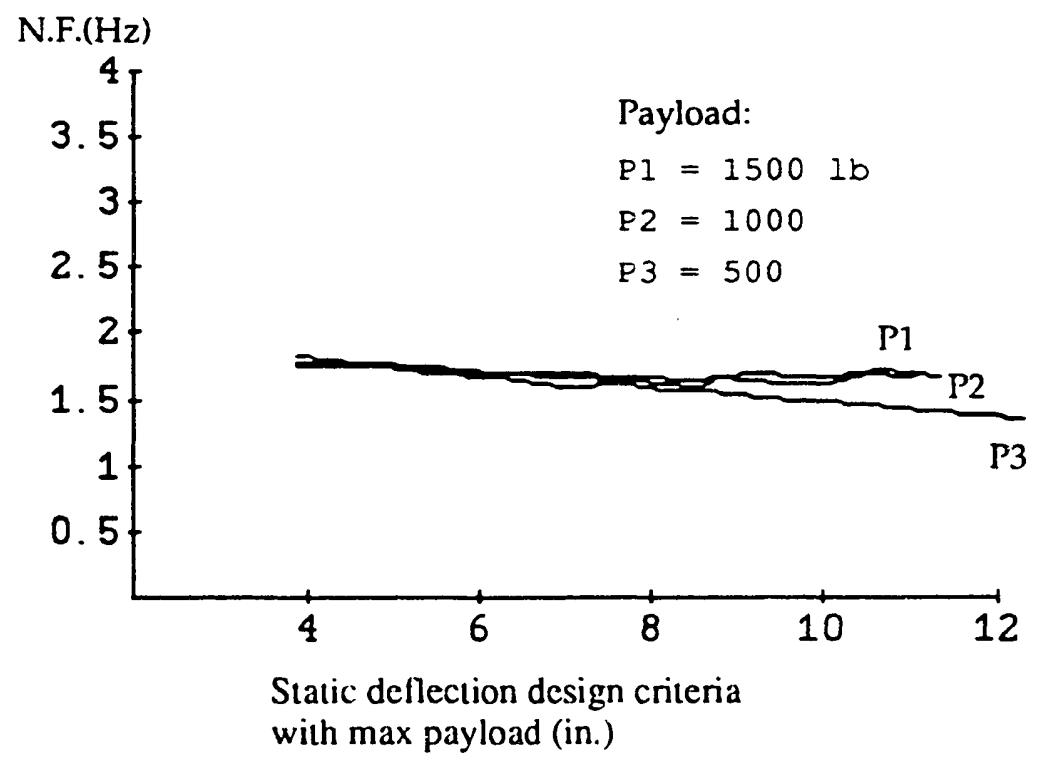

Fig. 28. Natural frequency without payload. 


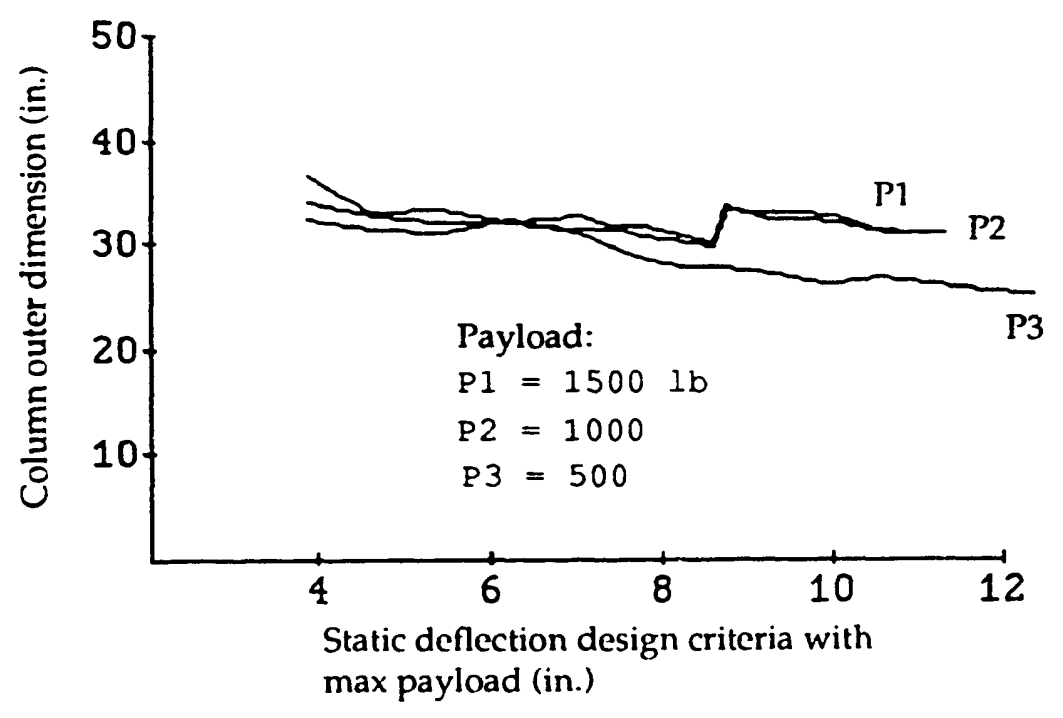

Fig. 29. Outer dimension of the column.

\section{Static deflection without payload}

As shown in Fig. 30, the static deflection without payload does not vary much, even though the static deflection design requirement is relaxed from 4 to 11 in.

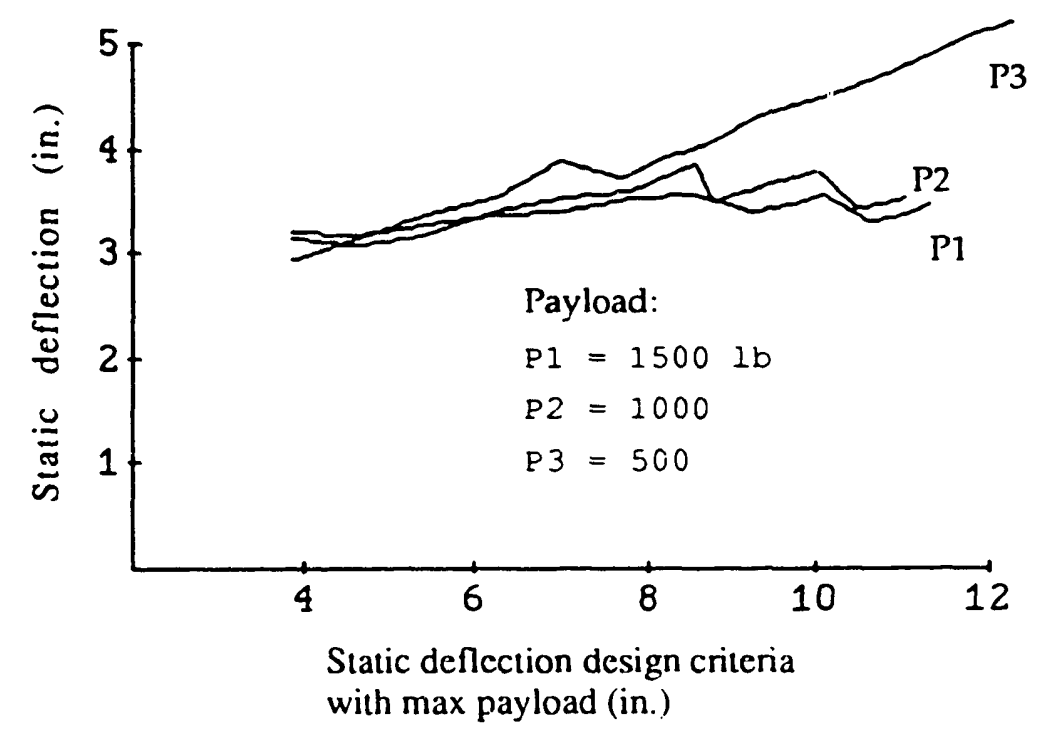

Fig. 30. Static deflection with no payload. 


\subsubsection{Case 4: Varying the Entrance Hole Diameter with Different Tank Sizes for the Folded-Type Manipulator}

In this case, tank radii of 24,31 , and $38 \mathrm{ft}$ and port diameters of 25 to $55 \mathrm{in}$. were considered. The payload was fixed to be $1000 \mathrm{lb}$ and the desired static deflection at the maximum payload was fixed to be 6 in. This case is the same as case 2 except that it is for a folded-type manipulator rather than a TSET.

\section{Weight of the manipulator}

If the entrance hole is too small, all of the design constraint conditions cannot be satisfied for the folded type. The line region in Fig. 31 represents conditions under which the links cannot be folded inside the column.

For the same weight as that required for the TSET, the folded type requires about a 10-in. larger entrance hole. For a 38-ft radius tank, if the entrance hole is less than 37 in., the design constraint conditions should be relaxed or another type of manipulator should be considered.

\section{Natural frequency}

The natural frequency with maximum payload does not change very much for entrance hole diameter variations, as shown in Fig. 32. The optimized design for various hole diameters will give about a $1.3-$ to $1.7-\mathrm{Hz}$ natural frequency with maximum payload. The natural frequency for no payload is shown in Fig. 33. For a small tank having a radius of $24 \mathrm{ft}$, a hole larger than 42 in. is not necessary; and for a 31-ft tank, a 51-in. hole will be large enough.

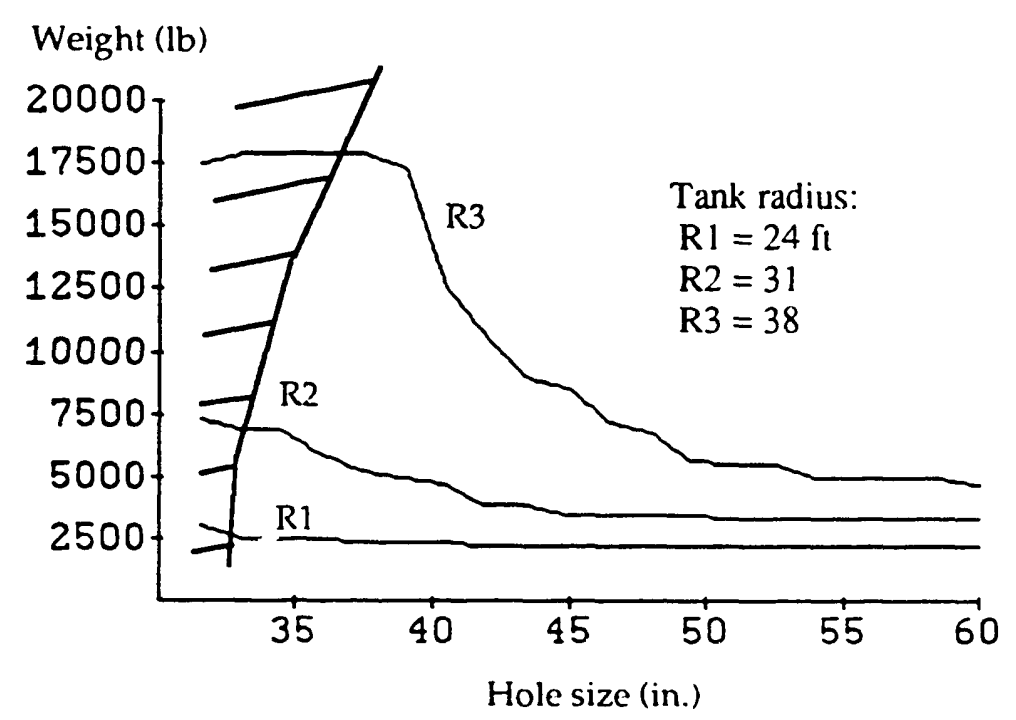

Fig. 31. Manipulator weight versus hole diameter. 


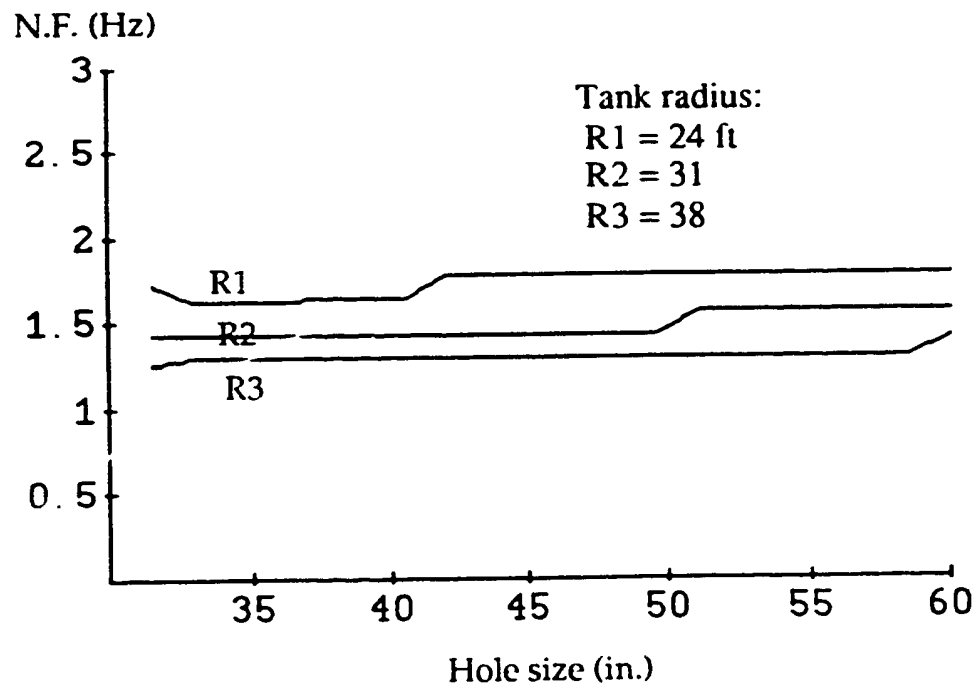

Fig. 32. Natural frequency with maximum payload.

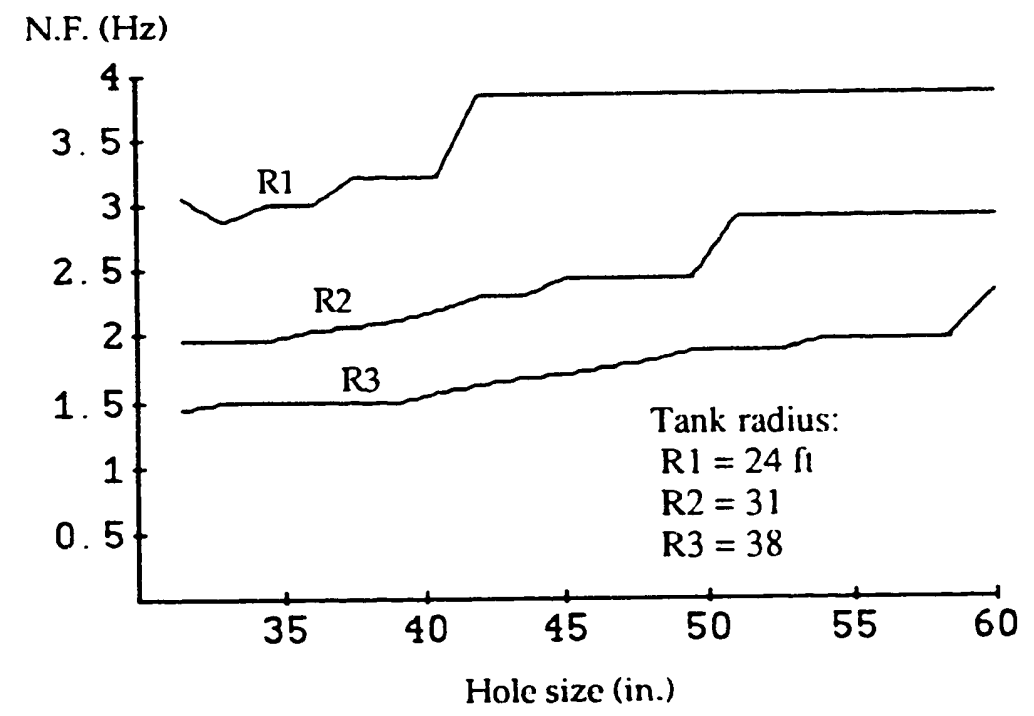

Fig. 33. Natural frequency without payload.

\section{Size of the column}

Figure 34 shows the proper range of the entrance hole diameter for different sizes of the tanks. For a tank with a radius of $38 \mathrm{ft}$, the hole should be larger than $37 \mathrm{in}$. A tank with a radius of $31 \mathrm{ft}$ should have an entrance hole of 33 to $51 \mathrm{in}$. For a 24-ft-radius tank, a larger than 42 -in. hole is not necessary. 


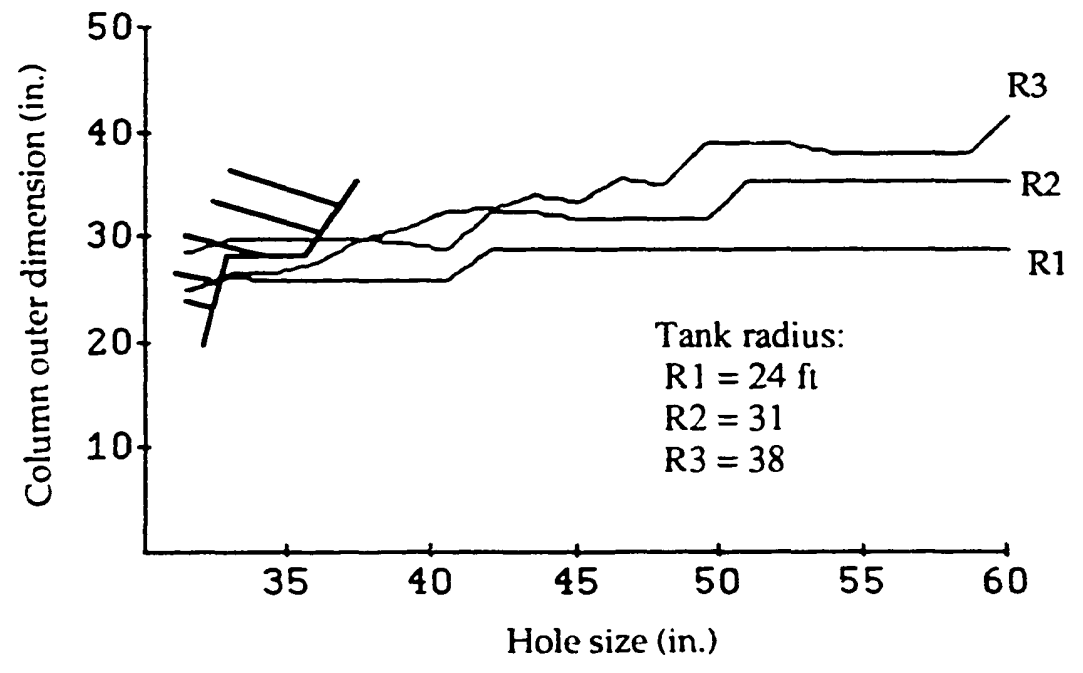

Fig. 34. Outer dimension of the column.

\section{Static deflection}

Since the static deflection design requirement was given per unit link length, the total static deflections depend on the manipulator horizontal reach, which is related to the tank size, as shown in Figs. 35 and 36. The line region in Fig. 35 represents conditions under which the links cannot be folded inside the column.

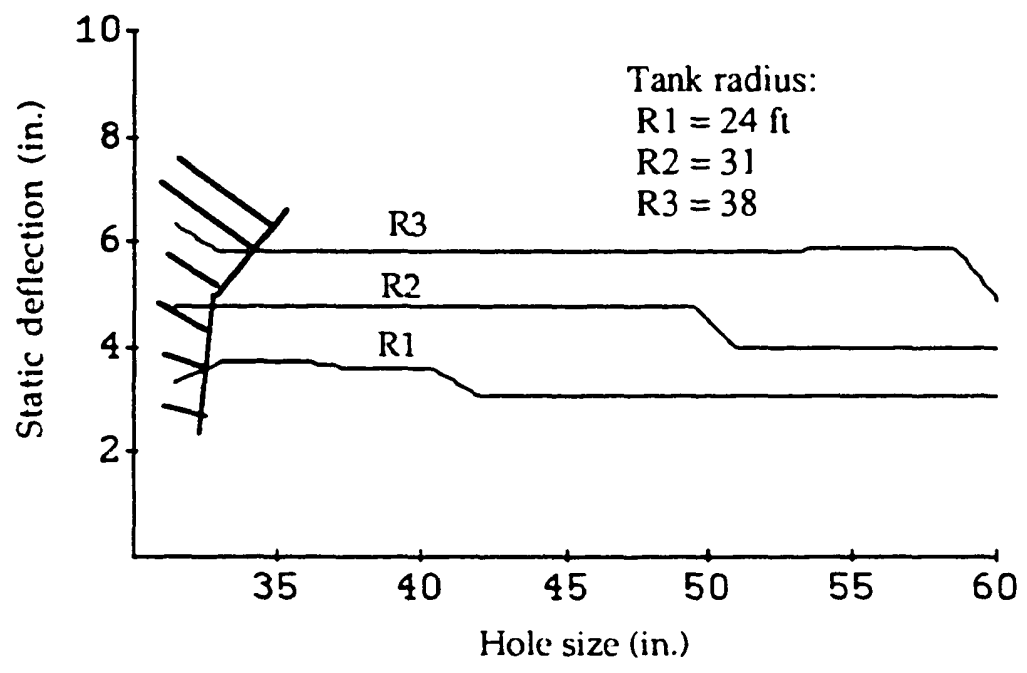

Fig. 35. Static deflection with maximum payload. 


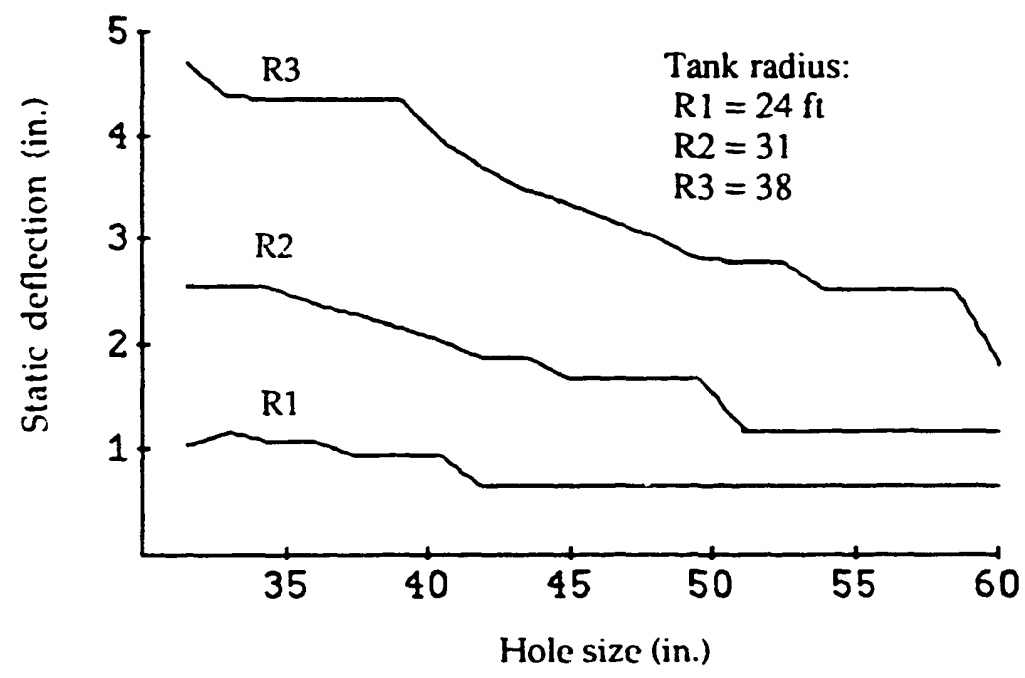

Fig. 36. Static deflection with no payload.

\subsection{CONCLUSIONS OF THE PARAMETRIC DESIGN ANALYSIS}

It is desirable to design LRMs to have conflicting characteristics such as minimum weight, minimum tower height, maximum structural natural frequency, and maximum actuator bandwidth. The parametric design study reveals quantitative suggestions of design criteria for LRMs. It gives quantitative estimations for weight, static deflection, and natural frequency of the manipulator with respect to a wide range of constraint condition parameters. It also shows the acceptable constraint condition ranges for TSET and FET manipulators.

\subsubsection{Static Deflection}

The static deflection design requirement should be carefully determined since static deflection is closely related to manipulator weight and structural natural frequency. If it is too severe, the weight of the manipulator will be unrealistically high. For typical underground storage tank applications (38-ft radius), a 4 to 6-in. static deflection requirement seems to be appropriate for a SET manipulator and a 6-8 in. requirement for a folded type. Since static deflection at the end-effector is somewhat large, it should be compensated for in trajectory planning using a static deflection model or an end-point position sensor. If the static deflection design requirement is more than 10 in., then the strength criteria will usually be the more prominent design criteria. Therefore, too large a static deflection requirement is meaningless. 


\subsubsection{Column Static Deflection}

Column static deflection is the major contributor to the end-effector deflection. Designing a very rigid column is important because it increases the structural natural frequency considerably and reduces the static deflection. The resulting large column also provides space into which the lower links can be folded. From a control viewpoint, column structural vibration will be key and uncontrollable with only the joint actuators. A bracing foot, which is extended from the bottom of the column, would aid in damping out horizontal vibration of the column.

\subsubsection{Natural Frequency}

The structural natural frequency of the system was not improved dramatically by designing the manipulator with severe design criteria or changing the type. It is reasonable to expect a system with maximum payload to have a fundamental natural frequency between 1 and $2 \mathrm{~Hz}$ and to design a control scheme including a trajectory planning approach to deal with the low-frequency structure.

\subsubsection{Entrance Hole Diameter}

An entrance hole diameter range is illustrated which is acceptable for different payloads and different horizontal reaches of the manipulator. If the available hole diameter is too small, the design procedure will increase the wall thickness of the links to meet the design criteria because the characteristic diameters of the links are very limited. This will result in an unrealistically heavy manipulator. If the hole diameter is increased, the weight of the manipulator will be decreased to a certain level at which it will remain. Since the thickness has reached a minimum and the design criteria are still satisfied, the size of the links does not need to be increased.

\subsubsection{Manipulator Type}

From the parametric study, one can conclude that the penalty of the folded-type manipulator is heavier weight to maintain the same deflection or larger deflection and lower natural frequency with the same weight. Generally, the folded type requires a larger hole to have the same performance as the TSET and the SET. The advantages of the folded-type manipulator lie in the resulting reduction in compressed manipulator length and, therefore, lower tower height and greater ease in transportation and installation. 


\section{ADVANTAGES AND DISADVANTAGES OF MANIPULATOR TYPES}

Each manipulator type has its own advantages and disadvantages. The SET with a rigid, nontelescopic column may have the simplest mechanism. However, the total length of all links and columns is the greatest, resulting in the highest support tower. The advantage of the folded type is to reduce the tower height by folding the manipulator link inside the column. If all links are completely folded and the column is telescopic as shown in Fig. 4, then the tower height can be reduced to $-28 \%$ of the tower height required for a SET with a nontelescopic column. These are the bounding cases with respect to tower height of the manipulator types considered.

The penalty of the folded type is the heavier weight required to maintain the same deflection or a larger deflection and lower natural frequency to maintain the same weight. Generally, the folded type requires a larger hole to have the same performance in terms of static deflection and natural frequency as the SET manipulators with either telescopic or revolute final joints. The advantage of the folded type are easier deployment inside the tank and easier extraction in case of power failure.

A TSET manipulator with a telescopic column provides one compromise between the two bounding cases discussed above. The use of a telescopic column and a telescopic final link will reduce the tower height to $\sim 58 \%$ of that of the SET with a rigid column. Since the manipulator is not folded, the links will have larger cross sections, which will give as small a static deflection as the SET.

Therefore, the choice of the manipulator type and its design involve trade-offs between a number of manipulator characteristics for example, weight, desired static deflection, natural frequency, and tower height. A general comparison of the advantages and disadvantages of three types of LRMs is given in Table 2.

It should be noted that truss structures have not been considered in the studies in this report. Such structures will have an inertia-to-area ratio advantage only when the link wall thickness required is impractically thin, which may result in local buckling, or when the link characteristic diameter is smaller than that required by design constraints. In the design procedure described in this report, reduced link characteristic diameters are obtained for the SET and the TSET. This indicates a potential for the use of truss structures. The general advantages of truss structures are commonly obtained by cutting holes or selectively reducing wall thickness in a square or hexagonal cross-section beam. It should be recognized, however, that manipulators with large cross-section links may have an obstacle avoidance disadvantage. 
Table 2. Advantages and disadvantages of three LRM types

\begin{tabular}{|c|c|c|c|}
\hline \multirow[b]{2}{*}{ Features } & \multicolumn{3}{|c|}{ Type } \\
\hline & Folded entry & $\begin{array}{c}\text { Telescopic } \\
\text { Sequential entry }\end{array}$ & Sequential entry \\
\hline Deployment & Easiest & Medium & Most Difficult \\
\hline Failure recovery & Best & Medium & Worst \\
\hline $\begin{array}{l}\text { Tower height } \\
\text { with and without } \\
\text { telescopic column }\end{array}$ & $\begin{array}{l}\text { Shortest } \\
(25 \text { or } 52 \mathrm{ft})\end{array}$ & $\begin{array}{l}\text { Medium } \\
\text { (47 or } 74 \mathrm{ft} \text { ) }\end{array}$ & $\begin{array}{l}\text { Highest } \\
(63 \text { or } 90 \mathrm{ft})\end{array}$ \\
\hline Backlash & Same & Same & Lowest \\
\hline Weight & Heaviest & Close to SET & Lightest \\
\hline End-point speed & Same & Same & Faster \\
\hline Natural frequency & Lowest & $\begin{array}{l}\text { Highest (for an } \\
\text { average end-point } \\
\text { location) }\end{array}$ & Medium \\
\hline Static deflection & Largest & $\begin{array}{l}\text { Smallest (for an } \\
\text { average end-point } \\
\text { location) }\end{array}$ & Medium \\
\hline
\end{tabular}




\section{ACTUATOR DYNAMIC EFFECTS}

The dynamics associated with hydraulic actuators that are likely to be used at the joints of LRMs will affect manipulator performance if the closed-loop actuator-load bandwidth is not significantly higher than the lowest structural resonant mode. Low joint (hydraulic) frequencies are likely. One objective of the design of a joint controller for LRMS is to increase the bandwidth to allow the introduction of damping at the lower structural mode frequencies. Hydraulic servovalve controlled motors and cylinders are typically modeled as third-order dynamic systems. Lag compensation provides improved low-frequency closed-loop stiffness. However, because hydraulic systems are typically underdamped, compensation designed to increase bandwidth is difficult. One approach is to increase leakage, at the expense of static stiffness. A second approach is to design lead-lag compensation to approximately cancel the complex roots. This may be sensitive to dramatic changes in system parameters. A third approach is the addition of a differential pressure feedback loop, which has the effect of increasing the damping ratio and extending servo bandwidth [Merritt 1967]. In addition to the stabilization problem associated with third-order dynamics, hydraulic servoactuators exhibit nonlinearities associated with valve characteristics, friction, and saturation. As in the case of dc motor drives, friction and saturation may significantly impact stabilization.

A brief study of the dynamics associated with actuators for the first pitch joint of an LRM was conducted. In this study, two different servoactuator types were considered: a hydraulic cylinder and a hydraulic motor and gear train. In both cases, similar results were obtained. Based on linearized models, the lowest open-loop natural frequency was about $0.5 \mathrm{~Hz}$, which came from the joint compliance due to compressibility of the hydraulic fluid. Utilizing position, velocity, and differential pressure feedback, the closed loop actuator bandwidth could be increased to approximately $2 \mathrm{~Hz}$. This bandwidth is close to the fundamental structural natural frequency when the upper arm and the lower arm of the LRM are assumed to be a clamped uniform beam. However, such a high bandwidth obtained by high feedback gain will not be realized due to saturation of the actuator. The practical actuator-load bandwidth is likely to be 0.5 to $1 \mathrm{~Hz}$, which is less than obtained with a small-signal, linear analysis.

The joint chosen for the actuator study is clearly the worst joint in the manipulator because of its high load capacity requirement. It is expected that higher actuator-joint bandwidths will be possible for the other pitch joint or joints (depending on the kinematic configuration chosen).

In conclusion, it is not likely that the actuator-load natural frequency will be significantly higher than the fundamental structural natural frequency. Care in the selection of actuators and in the design of joint controllers will be required to allow active structural damping. 


\section{SUMMARY AND CONCLUSIONS}

Long-reach manipulators, which will be required for a variety of applications in the Environmental Restoration and Waste Remediation Program, are likely to exhibit significant structural, as well as drive train, flexibility. Each application will present specific functional, kinematic, and performance requirements. This report focused on long-reach manipulation requirements, potential kinematic configurations, and manipulator design parameters and performance characteristics as impacted by constraints.

Several key design requirements and objectives were identified. The tank structure cannot be loaded, and recovery from failures must be possible. Manipulator deployment must be possible in the constrained space above the waste, and the manipulator workspace must provide coverage of the entire tank. Key objectives include the use of existing central ports for manipulator deployment and minimization of the height of the tower required to support the manipulator. For improved dynamic performance, the structural natural frequency should be maximized and the static deflection should be minimized; however, improvements in vibration damping are more likely to be significant. The objectives listed conflict with each other, and design trade-offs between these will be required.

In the kinematic study, it was shown that at least 5 positioning DOF are required because of the constraints involving the tank dimensions, the port through which the manipulator will be deployed, and the deployment clearance. The configurations considered included a roll joint, a prismatic joint, two pitch joints, and a final prismatic or pitch joint. In addition, a roll joint between the first two pitch joints was included, and its advantages and disadvantages were discussed. A comparison between a design that allows the lower links of the manipulator to be folded into the column for deployment and two designs that require sequential deployment of the manipulator was made. An approximate height of the support tower required for each of the three types of manipulators was determined, considering both a rigid coiumn and a telescopic column. The minimum tower height was required by the manipulator designed to be folded for entry and using a telescopic column. The maximum tower height was obtained for a manipulator with three pitch joints and a rigid column.

To suggest appropriate structural design specifications of the LRM, a parametric design study was performed to demonstrate trends of the manipulator structural characteristics for various constraint conditions. In general, less static deflection and a higher structural natural frequency are obtained with a manipulator deployed sequentially than for one designed for folded entry, because of the smaller characteristic diameter of the lower links required for folded entry. The structural natural frequency of the system was not improved dramatically by designing the manipulator with severe design criteria or changing the type. Because of dramatic changes in weight required for small 
static deflections, reasonable static deflections will be greater for FET manipulators than for SET manipulators. For the typical 38-ft-radius tank, the static deflection of FET manipulators is likely to be 6 to 8 in., while for sequential entry manipulators, it will be 4 to 6 in. Column static deflection was a major contributor to end-effector deflection. In general, as the entry port diameter was increased, the manipulator weight for the same static deflection criteria decreased until the minimum desired wall thickness was reached.

Selection of a manipulator type involves a trade-off between a number of design objectives. A comparison of the types of manipulators considered in terms of design objectives was made. Although truss structures were not considered to any extent in this report, their potential advantages were briefly discussed. In addition, the effects of actuator dynamics were also briefly discussed, with the general conclusion that for the LRMs considered, structural dynamics will dominate. 


\section{REFERENCES}

[DOE 1991] Department of Energy, Environmental Restoration and Waste Management, Robotics Technology Development Program, Robotics 5-Year Program Plan, 2, (88), 1991.

[Abdel-Rahman 1991] Tarek M. Abdel-Rahman, "A Generalized Practical Method for Analytic Solution of the Constrained Inverse Kinematic Probiem of Redundant Manipulators," The Int. J. Robotic Res., 10, (4), (August 1991).

[Blevins 1979] R. D. Blevins, Formulas for Natural Frequency and Mode Shape Van Nostrand Reinhold Company, 1979.

[Book 1975] W. J. Book, O. Maizza-Neto, and D. E. Whitney, "Feedback Control of Two Beam, Two Joint Systems with Distributed Flexibility," Trans. ASME: I. Dyn. Syst., Meas. Control, pp. 442-431 (December 1975).

[jansen 1992] J. F. Jansen, S. March-Leuba, D. S. Kwon, S. M. Babcock, B. L. Burks, R. L. Kress, and W. R. Hamel, Long-Reach Manipulation for Waste Storage Tank Remediation, FY 1991 Report, ORNL/TM-11999, Oak Ridge Natl. Lab., March 1992.

[Merritt 1967] Herbert E. Merritt, Hydraulic Control Systems, John Wiley \& Sons, Inc., New York, 1967.

[Paden 1988] Brad Paden and Shankar Satstry, "Optimal Kinematic Design of 6R Manipulators," Intl. J. Robotics, 7, (2), (March/April 1988).

[SILMA 1991] Cimstation User's Manual, Silma, Inc., Cupertino, Calif., 1991.

[Wenger 1990] P. Wenger and P. C hedmail, "On the Connectivity of Manipulator Free Workspace," J. Robotic Syst., 8 (6), 761-99, (1991).

[Wolfram 1988] S. Wolfram, MATHEMATICA: A System for Doing Mathematics by Computer, Addison-Wesley Publishing Company, Scotts Valley, Calif., 1988. 


\section{INTERNAL DISTRIBUTION}

1-25. S. M. Babcock

26. J. B. Barry

27. K. C. Bills

28. B. L. Burks

29. M. J. Haire

30. D. C. Haley

31. W. R. Hamel

32. J. N. Herndon

33-34. D. H. Hwang

35. J. F. Jansen

36. R. L. Kress

37. D. S. Kwon

38-42. A. P. Malinauskas

43. R. C. Mann

44. S. A. Meacham

45. J. O. Moore
46. M. W. Noakes

47. K. E. Plummer

48. B. S. Richardson

49. S. L. Schrock

50. J. O. Steigler

51. A. L. Wintenberg

52. H. R. Yook

53. ORNL Central Research Library

54-55. ORNL Document Reference Section

56. ORNL Laboratory Records

57. ORNL Laboratory Records-RC

58. ORNL Patent Section

\section{EXTERNAL DISTRIBUTION}

59. C. Bastin, Manager, LRM Reprocessing Projects, Division of Fuels and Reprocessing, Office of Facilities, Fuel Cycle, and Test Programs, NE-471, Department of Energy, Washington, DC 20545.

60. D. W. Bennett, Pacific Northwest Laboratories, P.O. Box 999, Richland, Washington 99352.

61. S. A. Couture, Lawrence Livermore National Laboratory, P.O. Box 808, L-591, Livermore, California 94550.

62. R. W. Harrigan, Sandia National Laboratories, P.O. Box 5800, Division 1414, Albuquerque, New Mexico 87185.

63. D. L. Herman, Fernald Management Company of Ohio, P.O. Box 398704, MS-81-2, Technology, Cincinnati, Ohio 45239-8704.

64. R. M. Hollen, Los Alamos National Laboratory, P.O. Box 1663, MS-J-580,Los Alamos, New Mexico 87545.

65. S. March-Leuba, Robotics and Manufacturing Division, Tecnatom, s.a., Avda. Montes de Oca, 1, 28709-San Sebastian de los Reyes (Madrid), Spain.

66. S. R. Martin, Fusion and Nuclear Technology Branch, Energy Programs Division, Departmentof Energy, X-10 Site, P.O. Box 2008, Oak Ridge, Tennessee 37831-6269.

67. C. R. Ward, Westinghouse Savannah River Company, Bldg. 773-A D-1134, Aiken, South Carolina 29808. 
68. B. Wilding, Westinghouse Idaho Nuclear Company, P.O. Box 4000, MS-3765, Idaho Falls, Idaho 83403-5104.

69. A. P. Williams, Westinghouse Hanford Company, P.O. Box 1970 T3-28, Richland, Washington 99352.

70. L. W. Yarbrough, Department of Energy, 12800 Middlebrook Road, MS EM-55 Trevion II, Washington, DC 20874.

71. Office of Assistant Manager for Energy Research and Development, Oak Ridge Operations Office, Department of Energy, P.O. Box 2008, Oak Ridge, Tennessee 37831-6269.

72-73. Office of Scientific and Technical Information, DOE Oak Ridge Field Office, P.O. Box 62, Oak Ridge, Tennessee 37831. 

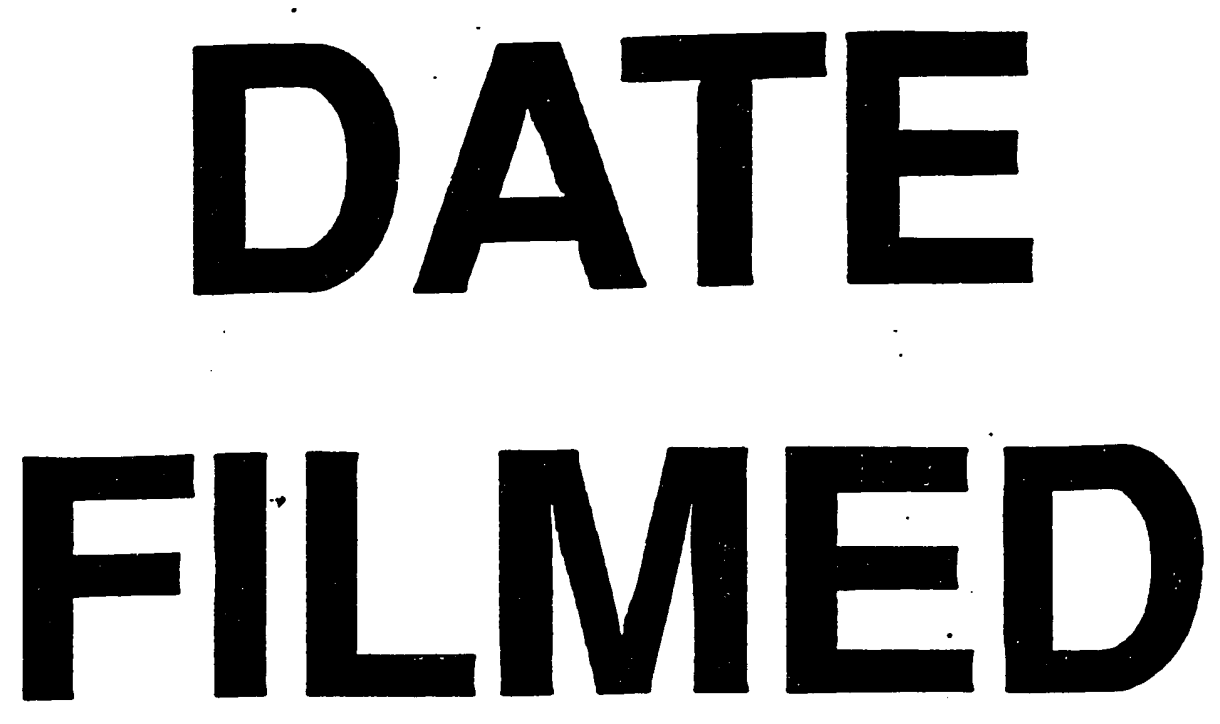

$1 / 10 / 94$
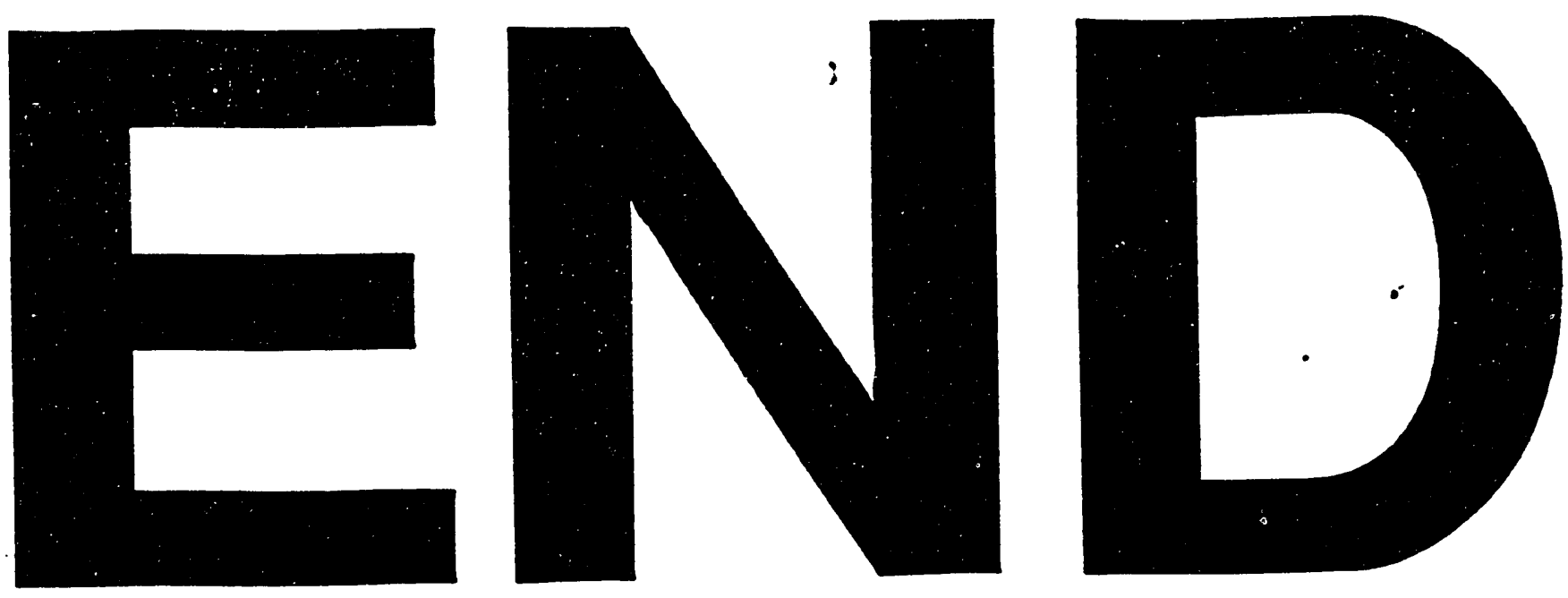